\title{
AN EXAMINATION OF DEMOCRATIC EDUCATIONAL PROCESSES WITHIN CONCERT BAND REHEARSALS
}

A Dissertation
presented to
the Faculty of the Graduate School
at the University of Missouri-Columbia
In Partial Fulfillment
of the Requirements for the Degree
Doctor of Philosophy
ALEC D. SCHERER
Dr. Brian Silvey, Dissertation Supervisor
MAY 2020


The undersigned, appointed by the dean of the Graduate School, have examined the dissertation entitled

\section{AN EXAMINATION OF DEMOCRATIC EDUCATIONAL PROCESSES WITHIN CONCERT BAND REHEARSALS}

presented by Alec D. Scherer,

a candidate for the degree of doctor of philosophy,

and hereby certify that, in their opinion, it is worthy of acceptance.

Dr. Brian Silvey

Dr. Wendy Sims

Dr. Brandon Boyd

Dr. Amy Knopps 


\section{ACKNOWLEDGEMENTS}

Thank you to Dr. Brian Silvey for your steadfast support, mentorship, and friendship. Words cannot express how much I appreciate the time and effort you have spent helping me become a better music teacher educator, writer, and researcher.

Thank you to Dr. Wendy Sims for joyfully sharing your wisdom. Your passion and dedication to all facets of higher education are an inspiration.

I would also like to thank my committee members, Dr. Brandon Boyd and Dr. Amy Knopps, for their support and encouragement throughout my doctoral program. I am grateful for the opportunities you have both provided me during my doctoral studies and am lucky to have you both as mentors.

Thank you to Dr. D. Gregory Springer. Without your friendship and mentorship, I would undoubtedly not be as far along in my trumpet player rehabilitation.

Finally, I would like to thank my family and friends for their loving support. 
ACKNOWLEDGEMENTS ...................................................................................................... ii

LIST OF TABLES ...................................................................................................... viii

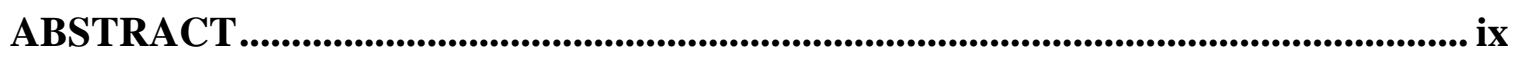

Chapter One ................................................................................................................................................. 1

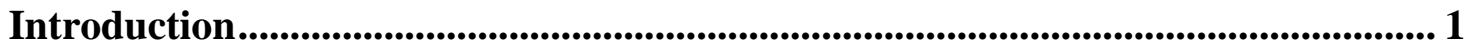

Problem and Purpose .......................................................................................................................... 3

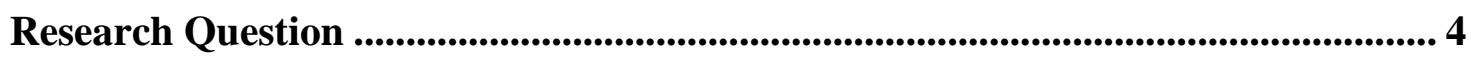

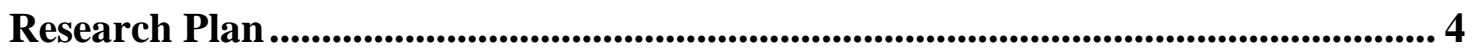

Importance of the Study ............................................................................................................ 7

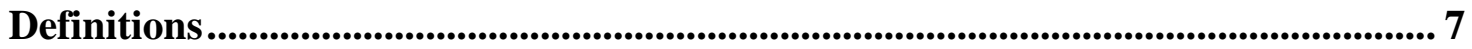

Chapter Two.............................................................................................................................................. 8

Democratic Educational Principles and Their Applications: A Review of

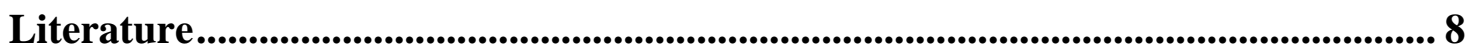

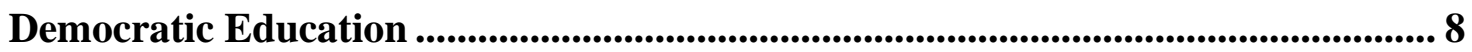

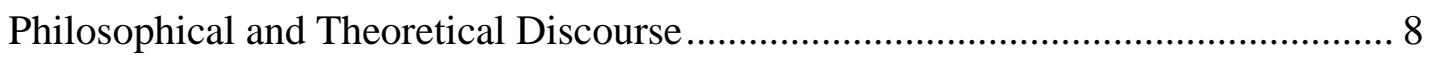

Non-Music Content-Specific Discourse........................................................................... 11

Process-Oriented Democratic Education ................................................................. 11

Product-Oriented Democratic Education .............................................................. 12

Music Education and Democracy ............................................................................................ 12

Concerns Regarding Implementation of Democratic Education ............................... 15 
Applications of Democratic Educational Principles in Non-Music Settings ......... 17

School or Program-Wide Implementation .......................................................... 17

Pre- and In-Service Educators' Experiences and Perceptions ............................... 19

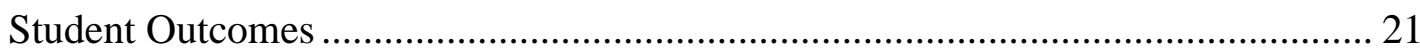

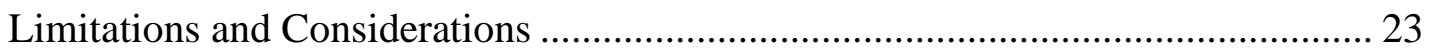

Applications of Democratic Education in Music................................................. 23

Teacher Beliefs and Experiences ................................................................. 24

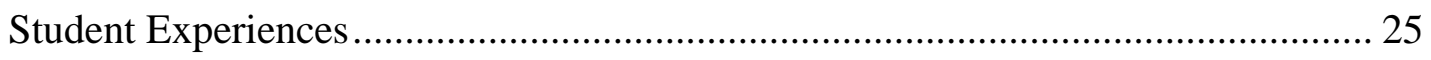

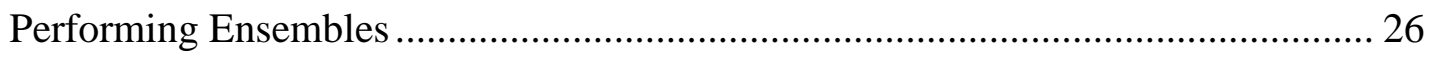

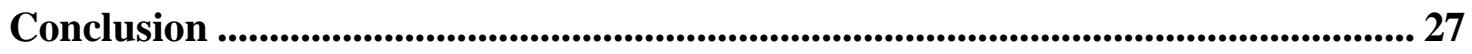

Chapter Three ................................................................................................................. 29

Collegiate Musicians' Experiences with Democratic Rehearsal Procedures ........ 29

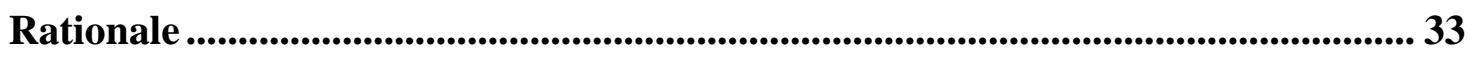

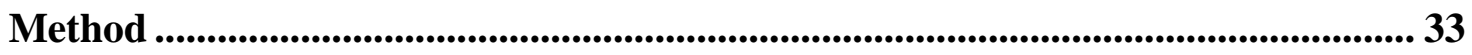

Philosophical Worldview \& Theoretical Framework ........................................... 33

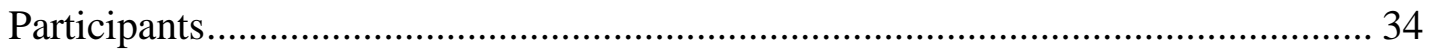

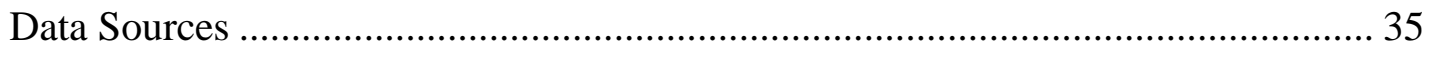

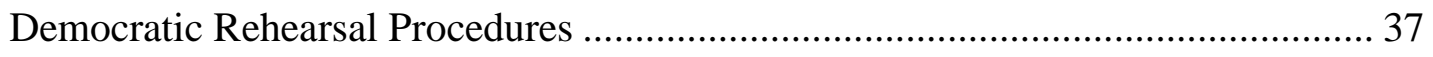

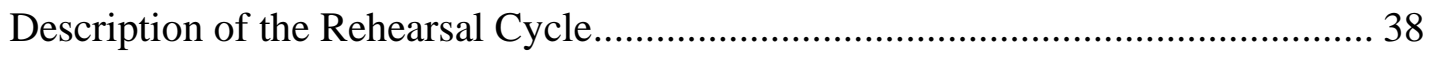

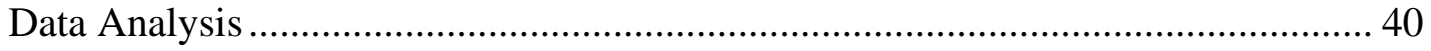


Trustworthiness

Epoché.

Findings.

Theme 1: The Value of Multiple Perspectives 43

Theme 2: Ownership and Musical Agency 44

Theme 3: Active Rehearsal Engagement 46

Theme 4: Providing Feedback 47

Theme 5: Concerns with the Amount of Rehearsal Time.

Essence.

Discussion. 50

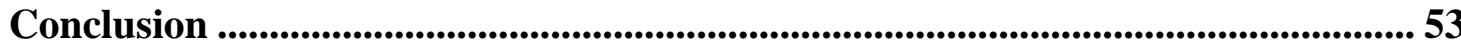

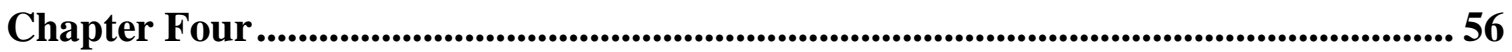

High School Band Directors' Perceptions and Applications of Democratic

Rehearsal Procedures in Concert Band Rehearsals ............................................... 56

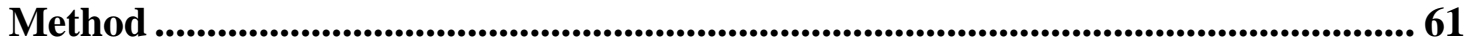

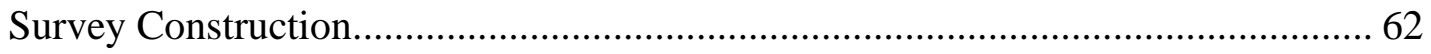

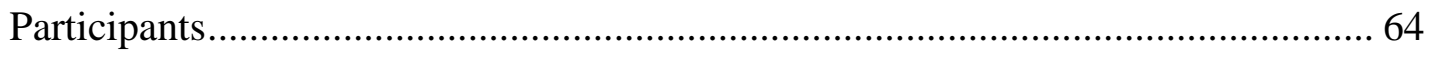

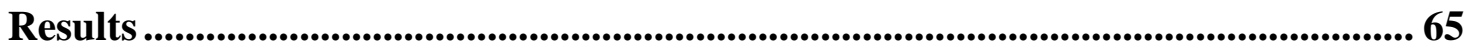

Beliefs About the Importance of Democratic Rehearsal Experiences ...................... 65

Frequency of Application of Democratic Rehearsal Procedures ........................... 66 
Perceptions of Advantages and Disadvantages of Democratic Rehearsal Procedures

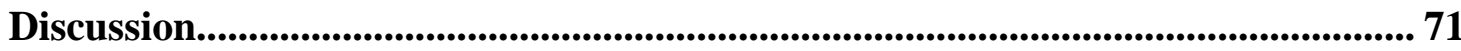

Implications for Teacher Educators................................................................ 76

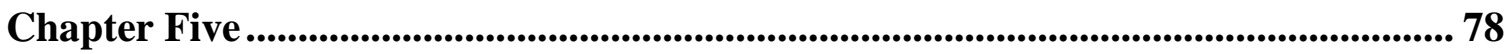

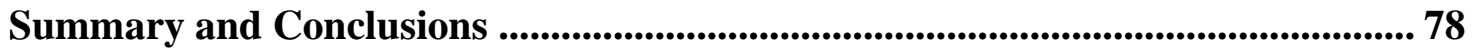

Research Question and Method..................................................................................... 79

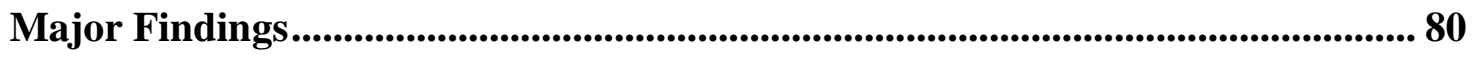

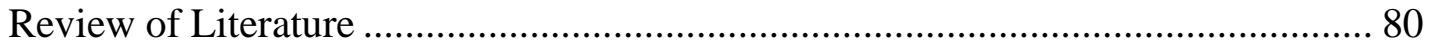

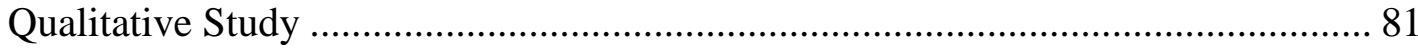

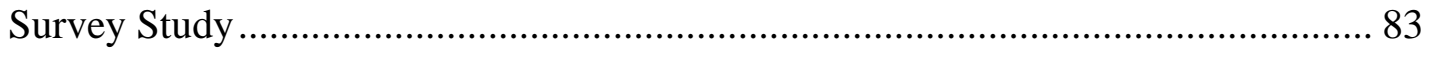

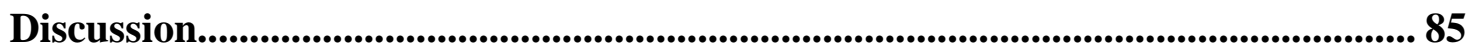

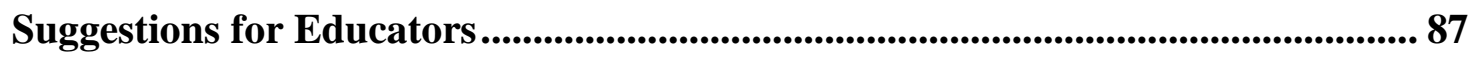

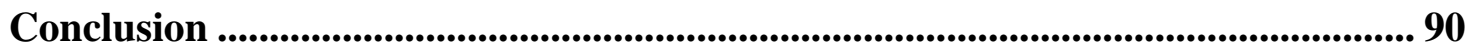

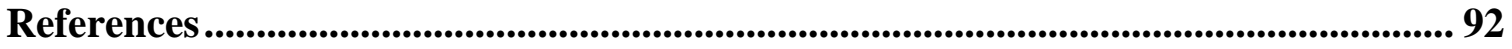

Appendix A

Appendix B ...................................................................................................................... 102

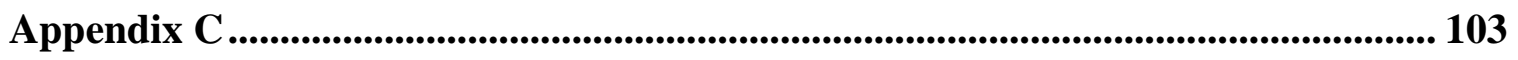

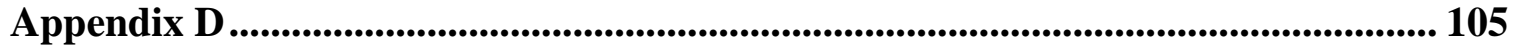

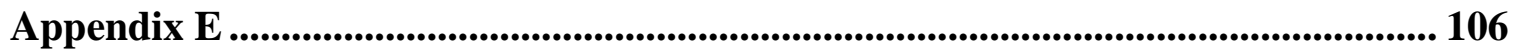




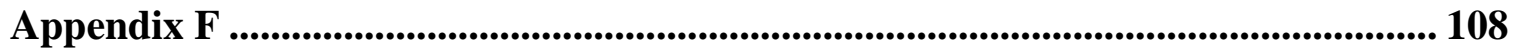

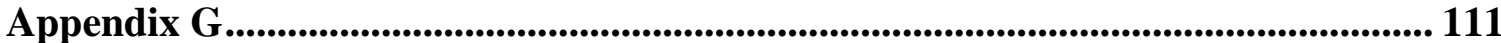

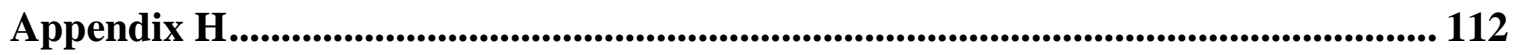

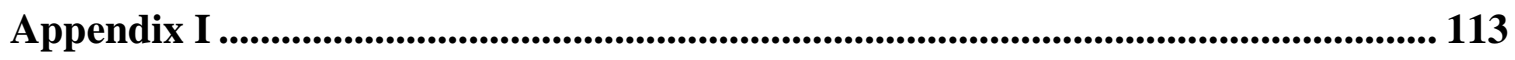

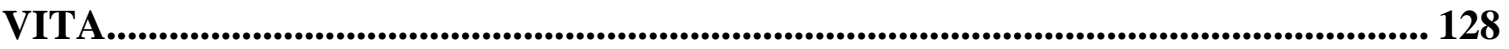




\section{LIST OF TABLES}

Table 1 Means and Standard Deviations of Democratic Rehearsal Procedures ...........67 


\title{
AN EXAMINATION OF DEMOCRATIC EDUCATIONAL PROCESSES WITHIN CONCERT BAND REHEARSALS
}

\author{
Alec D. Scherer \\ Dr. Brian Silvey, Dissertation Supervisor
}

\begin{abstract}
This dissertation consists of three projects that I designed to examine high school band directors' and collegiate musicians' experiences and perceptions of democratic educational processes within concert band rehearsals. The first investigation is a review of literature about democratic educational principles and their application in non-music and music classrooms. The second investigation is a phenomenological study of collegiate musicians' lived experiences with democratic rehearsal procedures in a concert band setting. Emergent themes included (a) the value of multiple perspectives, (b) ownership and musical agency, (c) engagement, (d) the ability to provide feedback, and (e) concerns with the amount of rehearsal time. The third investigation was a survey study of high school band directors' attitudes toward democratic rehearsal procedures, self-reported use in a typical rehearsal cycle, and perceived disadvantages and advantages. Results indicated that respondents believed several democratic rehearsal procedures were important for their students to experience; however, the frequency of their application was inconsistent. Taken together, results from these three projects indicated that democratic educational principles may be beneficial for students and teachers by providing opportunities for students to (a) actively engage in their learning, (b) exercise their agency, (c) work collaboratively, and (d) develop skills related to musical independence.
\end{abstract}




\section{Chapter One}

\section{Introduction}

Democratic education is based on the idea that schools play an important part in preparing students to be independent members of a democratic society (Dewey, 1916). Conditions such as (a) an open ideological environment, (b) collaborative problem resolution, (c) critical analysis and reflection, (d) concern for the welfare of others and the community, and (e) respect for persons' dignity and rights are necessary within a democratic society and can be applied in classrooms (Apple \& Beane, 1995). Discussion is a key component of a democratic society and both democratic and classroom discussions should be conducted in a nonrepressive and nondiscriminatory manner (Gutmann, 1987/1999) and special attention should be given to ensure that non-dominant viewpoints are considered (Gould, 2007, 2008). By adopting these democratic principles and incorporating them in a classroom environment, educators can encourage the development of desirable democratic and educational skills such as the four C's of $21^{\text {st }}$ century learning - critical thinking, communication, collaboration, and creativity (NEA, n.d.).

Educators adopt and adapt democratic principles based on their understanding of democracy and education (McNamara, 2019). One way to implement democratic principles is through a process-oriented approach which might include opportunities for students to work collaboratively to solve problems related to course content (Allen, 2011;

Luff \& Webster, 2014; Castro \& Grauer, 2010). A product-oriented approach may also be used and might be characterized by the addition of opportunities for students to apply content knowledge to contemporary societal discourse (Daly, 2002; Skovsmose, 1990). 
Democratic educational principles can positively affect student learning in nonmusic classrooms. Program-wide applications have improved attitudes toward school (Cleaver \& Riddle, 2014) and student well-being (Simó et al., 2016). In classroom environments, the use of democratic practices has aided students' development of problem solving and critical thinking skills (Brown, 2012), created open learning environments (McAvoy \& Hess, 2013; Pennisi, 2013), engendered feelings of ownership, efficacy, and achievement (Simovska, 2011), and increased student engagement (Boatright \& Allman, 2018).

Music educators and scholars have expressed interest in democratic educational practices. Woodford (2005) suggested that an embryonic approach—a scaffolded learning process led by the music teacher- that included opportunities for students to explore, examine, and defend their values would be beneficial for music educators and their students. Others have suggested that democratic classrooms should feature open learning environments (Allsup, 2003), spaces for student leadership and social justice (DeLorenzo, 2003), and opportunities for students to provide input related to curriculum offerings and course design (Draper, 2019). Democratic music educators might also consider how to develop students' musical voice through opportunities to engage in the same verbal and nonverbal process as experienced musicians (McNamara, 2019).

In a national survey of K-12 music educators' attitudes and behaviors related to democratic teaching, McNamara (2019) found that music educators frequently identified student agency and independence as outcomes of democratic education. However, respondents' application of democratic practices within their classrooms was limited. Findings also indicated that time was the biggest barrier preventing the adoption of 
democratic practices by K-12 music educators. Although the results from this survey included educators who teach large performing ensembles (i.e., bands, choirs, and orchestras), a closer examination of in-service high school band directors' beliefs and attitudes seems warranted because concert band directors are often identified as too reliant on teacher-centric instructional practices (Allsup \& Benedict, 2008; Kratus, 2007; Williams, 2011).

Previous investigations of democratic concert bands have focused on conductorless rehearsal models. Weidner (2019) found that collegiate musicians' rehearsal interactions increased in sophistication during a conductor-less rehearsal cycle. Results also indicated that rehearsal feedback became increasingly specific and focused on smaller musical phrases. Collegiate musicians have successfully prepared for a performance at a state music festival using a conductor-less model (Hedgecoth, 2018). However, Hedgecoth reported that a small number of ensemble members $(n=5)$ provided a majority of all rehearsal comments (78\%). Although participants indicated that they grew musically through the rehearsal process, their perceptions of the democratic experiences were mixed. Perhaps an embryonic democratic rehearsal process wherein democratic procedures are prepared, scaffolded, and facilitated by the instructor could provide a means of mitigating negative responses while encouraging the development of students' musical voice, agency, and independence.

\section{Problem and Purpose}

Concert band instruction is often criticized for relying on teacher-centric practices (Allsup \& Benedict, 2008; Kratus, 2007; Williams, 2011) that fail to meet contemporary music (NCCAS, 2014) and general education (NEA, n.d.) curricular objectives. Most 
secondary music instruction in the United States is provided in large performing ensembles (Elpus \& Abril, 2019). Therefore, examinations of instructional practices that provide students with opportunities to meet evolving curricular objectives without rejecting the traditional strengths of these ensembles is necessary. Democratic practices have been examined in general education (Cleaver \& Riddle, 2014; McAvoy \& Hess, 2013; Pennisi, 2013; Simovska, 2011) and music contexts (Allsup, 2003; McNamara, 2019), and results indicate that implementation can positively affect student learning. Previous investigations of democratic practices in concert bands have focused on conductor-less models (Hedgecoth, 2018; Weidner, 2019) that, while beneficial, represent a teaching approach so different from current practice it may seem impractical to in-service concert band directors. Considering that democratic education may aid in the development of students' musical voice, agency, and independence, further investigation of an embryonic democratic approach for concert band instruction seems warranted.

\section{Research Question}

I adopted an exploratory approach focused on experiences and perceptions of democratic education within concert band rehearsals. Specifically, I was interested in ensemble members' experiences and high school band directors' perceptions.

\section{Research Plan}

To begin my exploration, I reviewed extant literature about the philosophical background of democratic education, educators' discourse regarding incorporating democratic practices within music and non-music classrooms, and findings from previous investigations involving school and classroom settings. Through this process, I identified 
characteristic elements of democratic educational practices, common concerns, and the potential benefits of implementation for teachers and their students. I then examined what an embryonic democratic rehearsal cycle might be like from ensemble members' perspectives (Chapter 3) and perceptions and current use of democratic rehearsal procedures by in-service high school band directors (Chapter 4). Thus, this dissertation consists of three investigations designed to explore experiences and perceptions of democratic education and their potential application within concert band rehearsals.

The first investigation is a review of literature about democratic education.

Because a primary purpose of democratic education is to prepare students to become independent participants in society (Dewey, 1916) and the skills required for independence relate closely with contemporary educational objectives (NCCAS, 2014; NEA, n.d.), investigating how these principles have been applied in classrooms and their potential benefit for instrumental students and teachers seemed warranted. I paid specific focus to adaptations of democratic practices from multiple content areas. This review of literature was designed to identify characteristic democratic skills and pedagogical practices that provide music students opportunities to engage deeply with content within pre-existing band rehearsal structures.

The second investigation was a phenomenological study of collegiate musicians' lived experiences during a democratic rehearsal cycle. Previous investigations of democratic education within the concert band medium have focused on conductor-less ensembles (Hedgecoth, 2018; Weidner, 2019); however, democratic education does not inherently require a teacher-less model (Dewey, 1916; Gutmann, 1987/1999; Woodford, 2005). Therefore, I examined an embryonic or scaffolded democratic rehearsal process 
facilitated by the teacher (Dewey, 1916; Woodford, 2005). This study may provide band directors a better understanding of students' experiences in a rehearsal setting that more closely relates to current teaching practices than previously investigated conductor-less models. Music teacher educators might use these results to advocate for the adoption of democratic practices by collegiate ensemble directors. Furthermore, they might consider ways of preparing pre-service educators to incorporate democratic practices with students in their future ensembles.

The third investigation was a nationwide survey of in-service high school band directors' perceptions and applications of democratic rehearsal procedures. Although one researcher had investigated K-12 music teachers' attitudes and behaviors regarding democratic educational practices (McNamara, 2019), no previous investigations of high school band directors were found. Because most secondary students in the United States receive music education in large performing ensembles like concert bands (Elsup \& Abril, 2019) and concert band directors are often criticized for an over-reliance on teacher-centric practices (Allsup \& Benedict, 2008; Kratus, 2007; Williams, 2011), a better understanding of high school band directors' attitudes and current practices seemed justified. Understanding high school band directors' current attitudes and applications of democratic rehearsal procedures could inform music teacher educators' choices in their pre-service education curricula. Band directors may also find the results valuable when making decisions about how to provide students educational experiences that match current curricular objectives. 
In the final chapter of my dissertation, I synthesized the findings from my investigations, discussed potential implications, and offered ideas for future research. Suggestions for band directors and music teacher educators are presented.

\section{Importance of the Study}

This dissertation will provide a useful understanding of democratic educational principles, their effects on students and their experiences in the concert band rehearsal, and high school band directors' attitudes and applications of democratic rehearsal procedures in the United States. Examining an embryonic approach may provide a model that is more approachable than previously investigated conductor-less approaches (Hedgecoth, 2018; Weidner, 2019) for band directors who were prepared using teachercentric practices. Creating opportunities for students to apply their agency and make musical decisions may positively contribute to their classroom experience and learning outcomes.

\section{Definitions}

- High School Band Director: A band director teaching students in grades 9-12 or any subset thereof.

- Preservice Teacher: An undergraduate student enrolled in a teacher education program at a college or university.

- Embryonic Democratic Approach: A teacher facilitated democratic process characterized by scaffolded experiences that increasingly shift responsibility from the teacher to the students.

- Democratic Rehearsal Procedures: Rehearsal procedures that provide students opportunities to engage as active agents in the rehearsal process. 


\section{Chapter Two}

Democratic Educational Principles and Their Applications: A Review of Literature Educational scholars and philosophers have grappled with the idea of democratic education for over a century (Apple \& Beane, 1995; Dewey, 1916; Gutmann, 1987/1999). More recently, this discourse has extended into specific content areas such as math (Aguilar \& Zavaleta, 2012; Skovsmose, 1990), art (McDonnell, 2014), dance (Daly, 2002), and music (Allsup, 2007; McNamara, 2019; Tan, 2014; Woodford, 2005). Although many advocate for implementing democratic principles in classroom settings, the educational implications for students and teachers remain relatively unknown. This is particularly true for directors of large performing ensembles (i.e., bands, choirs, and orchestras) where only two investigations (e.g., Hedgecoth, 2018; Weidner, 2019) were found. Therefore, I will describe the underlying tenets of democratic educational practices, the discourse among educators and scholars regarding incorporating democratic practices within music and non-music classrooms, and findings from those who have applied these principles in school and classroom settings.

\section{Democratic Education}

\section{Philosophical and Theoretical Discourse}

The transmission of group values and rules is essential for the successful continuation of any organization. Imparting the skills and characteristics that allow new members to be active and independent participants becomes a challenge as organizations increase in size and complexity. Enculturation is particularly important in a democratic society because members' contributions can directly affect the evolution of society. In his seminal work Democracy and Education, Dewey (1916) suggested that the "ability to 
share effectively in adult activities thus depends upon a prior training given with this end in view" (p. 9). Schools are a primary means of providing educational training within a complex society. Therefore, according to Dewey, part of the purpose of schools and education should be to prepare students to be independent members of democratic society.

Formal educational preparation requires careful consideration of the content and processes students experience. Students absorb an unwritten curriculum through the teaching methods they experience. Dogmatic adherence to a system wherein students are empty vessels to be filled perpetuates students' reliance on and consumption of the opinions and solutions of an authority figure (Freire, 1968/2014). Conversely, a teaching method that "gives individuals a personable interest in social relationships and control, and the habits of mind which secure social change without introducing disorder" (Dewey, 1916, p. 115) prepares students to participate as active members as opposed to passive consumers. Apple and Beane (1995) described characteristics of this kind of classroom as including "shared interests, freedom in interaction, participation, and social relationships" (p. v). They also stated that the existence of fundamental democratic conditions like (a) the open flow of ideas, (b) faith in a collective capacity for problem resolution, (c) critical reflection and analysis, (d) concern for others' welfare, (e) concern for all members' dignity and rights, (f) understanding that democracy is an idealized set of values that only exist in practice, and (g) organizational and social support for democratic principles were necessary prerequisites for effective instruction that would allow students to develop democratic skills through the learning process. 
Because education can affect new members' understanding of democratic values and contribute to the development of democratic characteristics, all members must consider who should be allowed to make decisions about education and what limitations—if any — exist to their authority. Gutmann (1987/1999) referred to this idea— whereby all group members were extended opportunities to participate in decisionmaking through discussing their position in a nonrepressive and nondiscriminatory environment-as "conscious social reproduction" (p. 14). Engaging in a discursive process characterized by these principles develops rich contextual understanding as multiple perspectives are considered before final decisions are made. In a classroom setting, ensuring that dialogue is nonrepressive and nondiscriminatory becomes a primary role for the teacher.

The educational practices and curriculum objectives of a complex democratic society change concurrently as society evolves (Dewey, 1916). Contemporary curriculum objectives are increasingly based on skill development instead of simple content knowledge acquisition. The four C's of $21^{\text {st }}$ century learning — critical thinking, communication, collaboration, and creativity (NEA, n.d.)—and the three artistic processes of the 2014 National Coalition for Core Arts Standards-creating, performing, and responding (NCCAS, 2014) — demonstrate a contemporary emphasis on the development of functional skills for students. Therefore, educators who adopt democratic educational practices might provide students valuable opportunities to actively participate in the learning process while allowing them to cultivate desirable educational and democratic skills. 


\section{Non-Music Content-Specific Discourse}

The teacher plays a critical role in how democratic educational principles are applied in a classroom. At least eight different conceptions of democratic education have been identified (Sant, 2019) and each affects the classroom experience differently. During my review of the academic discourse specifically related to the application of democratic educational principles within non-music content-specific areas, I identified two basic approaches to democratic education-process- and product-oriented democratic education.

\section{Process-Oriented Democratic Education}

By focusing on the learning process, the unwritten curriculum in a classroom (i.e., how to function in a certain social environment) can be addressed. Luff and Webster (2014) advocated for participatory democratic practices that valued student knowledge and provided opportunities for students to work collaboratively to begin at the elementary school level. Similarly, Allen (2011) proposed a democratic model for math educators that provided students with opportunities to regularly work through problems within a mutual learning environment that included the teacher. Collaborative film projects can also be used to provide authentic experiences for students as they navigate multiple perspectives and reach compromises (Castro \& Grauer, 2010). Because a processoriented classroom is based on students actively collaborating with each other to discover new ideas or solve problems, the teacher often adopts a facilitator, moderator, or collaborator role while overseeing the process. 


\section{Product-Oriented Democratic Education}

A second approach to democratic education involved a product-based classroom orientation. Educators who focused on product-based applications valued the skills and understandings their discipline could provide that benefit students as members of a democratic society. For example, Skovsmose (1990) proposed that math educators should ensure that students are able to understand and apply mathematical concepts to contemporary societal discourse. Similarly, Daly (2002) identified several democratic principles (i.e., participation, critical thinking, reflective analysis, deliberation, and consideration of complex and sometimes ambiguous meanings) that he believed were essential democratic skills within a dance curriculum. Therefore, Daly suggested that dance educators should develop these elements of dance and emphasize their connection to democratic skills by preparing and analyzing dances created in response to larger political and social issues. Building on this idea of products situated within society, McDonnell (2014) proposed that art educators might provide democratic opportunities to students by allowing them to engage with pertinent contemporary—and potentially controversial — topics emphasizing how art can act as a social disruptor. The role of the teacher in a product-oriented democratic classroom is less clear than in a process-oriented educational setting, but one might surmise that the teacher may retain more authority as they relate content knowledge to contemporary societal discourse to cultivate democratic skills and understandings.

\section{Music Education and Democracy}

Although music educators — and particularly large ensemble directors (Kratus, 2007) — have relied historically on a teacher-centric model, there is growing interest in 
student-centered models that include teaching processes based upon democratic education. As with other content areas, disagreement exists concerning the role of the teacher in a democratic music classroom. Teachers might remove themselves from democratic-based activities by providing students open spaces for exploration with each other with minimal teacher influence (Allsup, 2003). Alternatively, a reciprocal teacherstudent relationship has been suggested wherein teachers are part of the learning environment while not completely dictating interactions (Allsup, 2007). Woodford (2005) described democratic music classrooms as "a public forum in which students practice gaining much needed experience in exploring, critically examining, and sometimes defending their values under adult supervision" (p. 87). Whether adopting an open, reciprocal, or facilitator role, teachers are essential to the democratic classroom experience.

As the most experienced member of the classroom, music teachers should design democratic learning environments carefully. One important consideration is how to develop and encourage students' musical voice. McNamara (2019) proposed that students' musical voice was an essential part of a democratic classroom and described it as consisting of "two categories of individual and social musical investigation and expression: production and creation" (p. 41, emphasis in original). Production related to the choices that musicians make regarding the instrument they play and the sound concept they desire, whereas creation related to the choices that musicians make when collaborating on music (e.g., interpretation). Musical voice then includes both the verbal and nonverbal decisions musicians make in response to their own conceptions of sound and the music being performed. 
Teachers are responsible for providing students opportunities to practice making musical decisions. DeLorenzo (2003) proposed a practical model for a democratic music classroom that consisted of three elements: (a) fairness, trust, and respect; (b) critical thinking related to musical structures, content, and repertoire; and (c) student leadership and advocacy for social justice in the classroom and community. Draper (2019) suggested that music teachers incorporate student input into curriculum offerings and course designs. By actively including student perspectives when constructing course offerings and curricula, music educators could create democratic learning environments that encourage students to develop their musical voice in an environment that supports the application of student agency through critical thinking skills and collaborative decision-making.

Based on the works of Dewey and Confucian philosophers, Tan (2014) outlined a transcultural theory of democracy for instrumental music education that consisted of five key themes - people, participation, equality, cooperation, and conflict. These themes resonate with conceptions of democratic education that have been previously discussed. However, because a primary purpose for Tan was to respond to large ensemble criticisms - like a reliance on an outdated authoritarian teaching model (e.g., Allsup \& Benedict, 2008; Kratus, 2007; Williams, 2011)—his explanation of each theme resulted in a justification of how large ensembles might already be considered democratic. For example, in Tan's explanation of his theme, people — which was based on the idea of governance by the people — he suggested that bands and orchestras already met this requirement because, in most situations, students can choose not to enroll in ensembles. 
Additional research is needed to better understand whether Tan's model is helpful for educators when creating democratic experiences for their instrumental music students.

Woodford (2005) addressed performing ensembles by writing that "students in performance classes should also be given frequent opportunities to formulate, clarify, express, and justify their own informed musical understandings and opinions with others through musical sounds, physical gestures, and the spoken word" (pp. 88-89). By incorporating opportunities to discuss elements of musical performance, Woodford suggested that "some kind of continually evolving and shared vision or collective understanding" (p. 89) might develop. The learning opportunities that Woodford proposed for inclusion in a democratic large ensemble closely related to the wording found in the National Core Arts Standards (NCAS) (NCCAS, 2014). For example, under the performing artistic process, the NCAS included selecting, analyzing, interpreting, evaluating, and refining music for personal and ensemble performances. Therefore, if democratic rehearsal practices naturally lend themselves to students developing these skills, as Woodford suggested, a better understanding of how democratic processes can be included in large ensembles seems warranted.

\section{Concerns Regarding Implementation of Democratic Education}

Regardless of how democratic educational practices were recommended for classroom use, researchers have identified potential issues and limitations with implementation. Allen (2011) suggested that math educators were hesitant about applying process-oriented democratic practices because of a heavy reliance on a traditional teaching and learning process. Aguilar and Zavaleta (2012) identified unfamiliar power structures based on empowering students to use their agency within the classroom and the 
ability of math educators to facilitate nonrepressive and nondiscriminatory discussions as notable concerns. Gould (2007) suggested that commonly held understandings of democracy by music teachers were often based on paternalist ideas that failed to consider potential democratic limitations such as a reliance on simple consensus. Therefore, facilitating a rich discussion that includes non-dominant views might be challenging, even for an experienced educator. Although the role of the teacher and how to effectively facilitate democratic educational experiences are frequently cited issues, relatively little empirical research has been conducted which, according to Aguilar and Zavaleta (2012), was the biggest barrier to continued discourse regarding the potential role of democratic education principles within the math field.

One of the primary purposes of democratic education is to prepare students to become independent, contributing members of democratic society. Whether focused on a process- or product-based approach, the democratic skills that students develop align with contemporary educational objectives (NCCAS, 2014; NEA, n.d.). The teacher plays a critical role in a democratic classroom because they scaffold experiences and moderate discussion - providing spaces for non-dominant perspectives to be heard and considered. Additionally, they must also empower students to apply their agency which requires teachers to not dominate the learning environment. Tensions related to this unfamiliar student-teacher relationship are common across content areas. However, little empirical evidence exists that substantiates the potential benefits and limitations of democratic educational practices. 


\section{Applications of Democratic Educational Principles in Non-Music Settings}

A thorough theoretical discussion and examination of democratic education provides the opportunity to consider how a democratic classroom might function. However, discourse alone does not provide an understanding of the benefits and limitations that teachers and students may experience when democratic educational concepts are applied. Based on the previously-discussed literature, it seems reasonable to conclude that teachers must carefully examine their own understanding of democracy and how to develop a learning environment that provides opportunities for students to gain experience practicing democratic skills. This process is not typical of most classroom environments because teacher-centric approaches have been most common (Allen, 2011; Kratus, 2007). Perhaps the increased preparation required of teachers and a lack of available models are two reasons that in situ investigations of democratic practices remain relatively scarce.

In the sections that follow, I discuss research addressing applications of democratic educational practices in non-musical settings including large-scale implementation and classroom level teacher and student experiences. Potential limitations identified in these examinations are discussed. Although democratic principles are similar to many other educational approaches (e.g., collaborative education and critical pedagogy), I only examined literature that included democratic education as a stated goal or inspiration because it provided an underlying philosophy.

\section{School or Program-Wide Implementation}

Large-scale implementation of democratic educational practices presents unique challenges and opportunities for schools. The Sudbury Valley Day School (SVDS) 
adopted a self-directed participatory democratic approach to schooling wherein classes were developed only when groups of students expressed interest (Gray \& Chanoff, 1984). In this approach, students and staff shared power when making decisions-including rules and regulations. Because classes were only created when enough interest was present, faculty roles changed from the design and implementation of curricula to facilitating student investigations and providing resources. Although this approach was radically different than standard educational experiences, a survey of SVDS graduates from an 13-year period (1968-1981) indicated that many alumni who chose to pursue a collegiate education had completed or were completing a bachelor's degree or higher and that those who began additional studies but did not complete them elected to unenroll for personal reasons, not academic ones (Gray \& Chanoff, 1986). Additionally, 37 (53.62\%) of the 69 respondents reported that their experience at SVDS did not negatively impact their collegiate studies. The practices adopted at SVDS — where the average enrollment from 1968-1981 ranged between 55 and 75 students (Gray \& Chanoff, 1986)—were comprehensive and may be challenging for other schools to implement. However, the potential benefits regarding students' agency and feelings of empowerment might warrant further investigation.

Cleaver and Riddle (2014) found that eleventh and twelfth grade Australian students at an urban alternative high school with a music-based curriculum expressed increased positive attitudes toward school when compared to beliefs about their previous traditional educational experiences. The researchers suggested that students' positive response to the school environment was likely based on a climate that encouraged student autonomy and personal responsibility. Even minimal implementation of democratic 
practices, such as a collaborative student-teacher relationship, has been found to positively affect school atmosphere and student well-being (Simó et al., 2016). Although large-scale implementation may be beneficial, the resources required can be a potential limiting factor for underfunded or understaffed schools such as those found in rural areas (Schmuck \& Schmuck, 1990). Implementing democratic practices at a school or program-wide level requires considerable time and resource investment from administrators and teachers.

Based on these findings, adopting some democratic educational practices, such as a more collaborative or reciprocal student-teacher relationship, might positively contribute to student well-being. However, adopting democratic practices at an institutional level may be impractical due to the amount of resources required.

\section{Pre- and In-Service Educators' Experiences and Perceptions}

Researchers have investigated pre- and in-service teachers' beliefs about democratic education. Teachers at the School of Education of the Gambia College who completed a two-day workshop based on multiple conceptions of democracy thought that democratic education was a useful means of developing democratic citizenship (Schweisfurth, 2002). Additionally, 91\% of teachers who participated indicated that they believed democratic teaching would positively impact their teaching efficiency. Teachers who participated in a weeklong dance workshop designed to demonstrate how dance instruction could be integrated in their K-12 classrooms as a means of facilitating democratic discussion indicated increased feelings of trust, empathy, and reflectiveness at the end of the experience (Catalano \& Leonard, 2016). Investigating the beliefs and applications of nine self-identified democratic educators, Collins et al. (2019) found that 
democratic teachers valued the development of a reciprocal relationship with students because it encouraged students to exercise their agency and actively engage in the learning process. Participants suggested that it was important to teach students how to engage in a democratic process while providing spaces and structures for them to practice democratic skills. Teacher reflection was considered essential in a preparation process that differed from more traditional approaches. Additionally, participants identified lack of support from administrators, colleagues, and parents as an obstacle, but suggested that careful explanation of democratic educational processes and the reasons behind them could aid in resolving potential issues.

Ross and Yeager (1999) examined prospective elementary teachers' understanding of democracy. Based on descriptions from their students' writing, the researchers sorted papers into three levels of understanding with nearly two-thirds of students being placed in the lowest category, which was characterized by a basic understanding of democratic citizenship. Across all levels, students' writings did not include balancing individual and societal needs nor an understanding of cultural and social diversity. Ellis (2013) examined pre-service English teachers' experiences with a democratic process based on the construction of their course syllabus and curriculum. Participants' responses were mixed with many indicating that negotiating the curriculum as a learning community was educationally valuable, whereas others appreciated the experience but believed their future students would not be able to participate in a similar process because children lacked knowledge of what they should know. Although preservice teachers' understanding of democracy and beliefs about potential classroom benefits varied, in-service teachers who had applied or learned about democratic 
education believed that implementation yielded positive outcomes for students. It appears that with appropriate training and preparation, current and future teachers might find democratic practices valuable.

\section{Student Outcomes}

Democratic educational practices applied at the classroom level have affected student outcomes positively. Children as young as nine have successfully participated in deliberative discussion when presented with a relevant topic and appropriate preparatory instruction (Hauver, 2017). The use of democratic practices in a modified literature circle format provided third grade students the opportunity to clarify reading comprehension issues (e.g., vocabulary, factual information, and understanding character actions) and aided students' development of problem solving and critical thinking skills (Brown, 2012). In a series of interviews, Helwig (1998) investigated Canadian students' ideas of political democracy. Age was found to be a predictor for political preference with younger children preferring a system involving consensus, whereas older children preferred a more direct democratic approach. Age and gender have also been found to be predictors of attitudes toward civic engagement for black and Latino middle school students (Jagers et al., 2017).

Students' positive beliefs have increased when provided regular democratic classroom experiences. Pennisi (2013) incorporated democratic practices such as dialogue, consensus building, active listening, and opportunities for student agency in an eighth-grade art class with the hope of increasing the students' interest in art. Findings indicated that implementation created an open learning environment which allowed students to explore and develop their voices. Dutch elementary and middle school 
students engaged in a participatory democratic process designed around a community improvement project expressed feelings of ownership, efficacy, and achievement (Simovska, 2011). Based on these findings, it seems that when applied thoughtfully, democratic educational practices can be beneficial, even for young students.

As students mature, more sophisticated democratic practices can be applied to increasingly complex societal issues. High school students who participated in a democratic literature selection process demonstrated increased engagement by applying student agency, participating in active inquiry and reflection, and demonstrating empathy when reading student-selected and teacher/state-mandated literature (Boatright \& Allman, 2018). Awareness of social justice issues increased in nearly $90 \%$ of students who participated in a math class that included democratic inquiry to investigate social issues like racism and socio-economic discrimination (Brelias, 2015). As part of a fouryear longitudinal study, McAvoy and Hess (2013) examined the effect of democratic deliberation regarding controversial political issues on high school students' classroom experiences and future political and civic engagement. Their findings indicated that allowing students the opportunity to engage in democratic deliberation created a more open classroom environment. In addition, they suggested several best practices for facilitating student discussion: (a) actively engaging students in deliberations, (b) ensuring students prepared for deliberation, (c) requiring a wide cross-section of the class to voice their position, and (d) encouraging students to engage with each other and not the teacher. 


\section{Limitations and Considerations}

Although researchers have found many positive outcomes for students when applying democratic educational practices, certain limitations have also been identified. For instance, fairness is an important part of democratic decision-making and discourse. Therefore, democratic practices are less effective when unequitable environments develop (Hauver, 2017; Helwig, 1998). It can be tempting for educators to create inauthentic learning environments that over-simplify the challenges of engaging in community improvement projects because the reality of government bureaucracy can negatively affect students' perceptions of democratic systems (Simovska, 2011). Reliance on discussion can become problematic if students feel uncomfortable participating in discussion-based activities (Hemmings, 2000) or certain perspectives are neglected (McAvoy \& Hess, 2013). Developing a democratic classroom requires that educators thoughtfully prepare experiences such as democratic discussion in order to increase the likelihood that these challenges are mitigated.

\section{Applications of Democratic Education in Music}

Music educators and scholars have advocated for creating classrooms and ensembles that embrace democratic educational principles (Allsup, 2007; DeLorenzo, 2003; Draper, 2019). However, the means through which these practices might be applied varied by author. Although some music educators have emphasized providing student agency through democratic practices that included the teacher (Tan, 2014; Woodford, 2005), others have suggested adopting an open approach to music instruction (Allsup, 2016). Regardless, careful consideration during design and facilitation is required to ensure the development of a positive learning environment that includes non-dominant 
viewpoints (Gould, 2007, 2008) such as the use of democratic principles in music ensembles.

\section{Teacher Beliefs and Experiences}

As with any educational method, applying democratic educational practices successfully in the music classroom relies on the teacher. McNamara (2019) conducted a national survey of K-12 music teachers' attitudes and behaviors toward democratic teaching practices. Findings indicated that educators frequently described democratic practices as a means of developing student agency and independence. Additionally, respondents expressed positive attitudes toward democratic practices that provided these opportunities through musical choices such as selecting their instrument. However, educators held less favorable attitudes toward collaborative tasks like discussion and repertoire selection. Time was identified as the biggest barrier for implementation. In another study, McNamara (2019) investigated two collegiate teachers who self-identified as democratic educators and applied democratic principles within collegiate instrumental music education coursework. The teachers' definitions of democracy influenced the kinds of activities they provided their students. However, both educators scaffolded learning experiences by providing students more responsibility as their understanding of democratic educational practices and music content became increasingly sophisticated. Based on these findings, it seems that music educators may find incremental implementation of democratic practices that encourage student agency and independence beneficial. 


\section{Student Experiences}

Evidence that democratic music classrooms promote positive student experiences and outcomes may encourage music educators to consider implementation. Silverman (2013) applied democratic principles in a music listening course by engaging participants in the music repertoire selection process. Unfamiliar with the modified power structure, participants initially resisted, but at the end of the experience acknowledged that selecting music encouraged critical reflection and analysis skills. Students in community ukulele groups similarly resisted opportunities to apply their agency when asked to select repertoire (Gieblehausen \& Kruse, 2017). Student resistance in these studies might have been based on expectations for music classrooms developed through years of teachercentric experiences. Replication of these studies is necessary to better understand student and teacher experience with modified teacher-student relationships.

Democratic practices have also been applied in small composition units. Allsup (2003) found that secondary students enjoyed working together collaboratively in an open environment and that they described the experience as meaningful. Elementary students engaged in a democratic composition project were successful in developing processes that led to unique ways of performing music (Swanson, 2015). However, wide variation in music skill within groups posed challenges that reduced full engagement in the democratic collaborative process. Small group activities provided students valuable opportunities to engage in democratic experiences, but without the guidance of the teacher, differences in ability led to unbalanced structures that limited the benefits of democratic engagement. 


\section{Performing Ensembles}

Because performing ensembles are the means by which most secondary music education is provided (Elpus \& Abril, 2019), they seem to be an area worthy of examination. Using Tan's (2014) list of democratic characteristics of instrumental performing ensembles as an analysis framework, Berglin (2015) conducted a case-study of an all-female contemporary collegiate a cappella ensemble with a democratic leadership structure. All members of the choir were expected to contribute based on their strengths and the needs of the ensemble. Because of the student-led nature of the ensemble, Berglin concluded that a cappella groups that apply democratic leadership do not fully comply with Tan's proposed characteristics. Themes of "sstepping up, vulnerability, and transmission" (p. 51) provided evidence of a positive learning community that developed through the democratic process.

Hedgecoth (2018) investigated student experiences and learning outcomes in a collegiate concert band modeled on a conductor-less ensemble. Participants were members of an auditioned concert band at a large Midwestern university who were preparing a piece of music for a performance at the state music education conference. A small leadership team-consisting of conductor- and self-selected ensemble memberswas tasked with preparing materials and leading rehearsals. Findings indicated that rehearsal dialogue was shared by both males and females, but only $30 \%$ of the ensemble participants provided comments, with five participants making $78 \%$ of all rehearsal comments. Most participants expressed excitement when first presented with the idea of democratically-run rehearsals, and many ensemble members $(76 \%)$ indicated feeling like they grew musically through the rehearsal process. However, responses indicated that 
many participants did not want to repeat the experience. It is likely that these mixed feelings were due to an overall negative social experience expressed by some of the participants who noted that all voices were not respected "and [that] frustrations grew as a result of dominant personalities commandeering the rehearsals" (p. 18). Further exacerbating the social dynamic, a few participants felt particularly ignored during the rehearsal process. Perhaps had the conductor adopted a facilitator role as opposed to removing themself completely during the rehearsal process these issues could have been reduced.

Weidner (2019) also examined a collegiate concert band modeled on a conductorless ensemble. He identified three stages of ensemble interaction: (a) novice uncertainty, (b) individuals and basics, and (c) rule making and strategizing. In stage one, participants primarily used large run-throughs rehearsals with little analysis resulting in slow progress. During stage two, individual leaders began to guide strategic discussion and specific musical phrases were addressed; however, ensemble members became frustrated. The final stage was comprised of the development of formal roles, responsibilities, and policies legislating these responsibilities. Additionally, rehearsal strategies became more sophisticated and details beyond simple accuracy were rehearsed.

\section{Conclusion}

Democratic educational practices appear to be valuable tools for educators. Successful implementation requires careful consideration and preparation of democratic and content area skills. The role of the teacher may vary based on their beliefs about democratic education; however, acting as a facilitator is one important way that teachers 
can help reduce potential problems such as limited representation of non-dominant perspectives.

Students benefit from democratic educational experiences. Large-scale implementation can increase student engagement and positive feelings toward school. Involvement in democratic practices at the classroom level allows students to develop their agency while reflecting on, analyzing, and discussing multiple perspectives. Through this process, students are provided the opportunity to develop the skills and habits of mind necessary for independence.

Music education has a long history of teacher-centric practices-particularly in performance-based classrooms (Allsup \& Benedict, 2008; Kratus, 2007; Williams, 2011). Adopting democratic educational principles is one way for music educators to enact a more student-centered approach. Adaptations for large performing ensembles have focused on conductor-less models that yielded mixed results for student participants. Research is needed to understand how models that do not entirely remove the teacher while still providing democratic experiences might affect students' perceptions. Not only does this model allow the teacher to facilitate discussion and ensure that multiple viewpoints are considered, it may also provide a more approachable entry point for music educators. 


\section{Chapter Three}

\section{Collegiate Musicians' Experiences with Democratic Rehearsal Procedures}

Large performing ensembles-particularly in secondary schools where they serve as the primary source of students' music instruction (Elpus \& Abril, 2019)—are a strong tradition within the educational system in the United States. Historically, concert bands, orchestras, and choral ensembles have been led using a teacher-centric model (Kratus, 2007). However, recent curriculum reform (i.e., the National Core Art Standards (NCAS) (National Coalition for Core Arts Standards [NCCAS], 2014) has resulted in an increased call for experiential and participatory ensembles (Marcetti, 2019).

Democratic educational practices may provide one approach for moving toward a classroom that embraces participatory experiences. A democratic classroom may be characterized as one wherein students actively collaborate with each other-and the teacher - through discussion to make decisions that directly impact their learning (Dewey, 1916). As the authority figure and content expert, the teacher plays an important democratic role by ensuring that discourse proceeds in a nonrepressive and nondiscriminatory manner (Gutmann, 1987/1999). Additionally, discussion should represent multiple viewpoints, including non-dominant perspectives (Gould, 2007, 2008). Teachers may also adopt an embryonic democratic approach, a process of providing scaffolded experiences that gradually shift responsibilities to students (Dewey, 1916; Woodford, 2005). Regardless of how democratic practices are implemented, the underlying goal is to provide students opportunities to apply their agency in order to prepare them for future independent participation in larger societal structures (i.e., democratic society). 
Applications of democratic educational practices have been examined in general education settings. For example, students at an urban high school that adopted participatory democratic practices described an open learning environment that allowed them to function autonomously which resulted in increased feelings of responsibility and positive attitudes toward school (Cleaver \& Riddle, 2014). At the classroom level, democratic educational practices have been investigated in social studies and politics (Helwig, 1998; McAvoy \& Hess, 2013), math (Brelias, 2015), language arts (Boatright \& Allman, 2018; Brown, 2012; Ellis, 2013), and art (Castro \& Grauer, 2010; Pennisi, 2013) classrooms. Findings from these studies indicated students' increased feeling of openness (McAvoy \& Hess, 2013; Pennisi, 2013), empowerment and achievement (Simovska, 2011), improved problem solving and critical thinking skills (Brown, 2012), and increased student agency, empathy, and reflection (Boatright \& Allman, 2018). Additionally, issues relating to fairness and privilege (Brelias, 2015; Hauver, 2017; Helwig, 1998; McAvoy \& Hess, 2013) and lack of student expertise (Ellis, 2013) were identified. In an investigation of nine self-identified democratic educators, Collins et al. (2019) found that participants valued the reciprocal relationship created in a democratic classroom because their students were empowered to use their agency and more actively participate in the learning process. However, their participants made it clear that democratic skills needed to be taught in addition to other curricular content. Furthermore, teacher reflection and preparation were essential. Based on these findings, it seems that democratic practices can positively affect student and teacher experiences when carefully prepared and applied. 
In response to changing curricular objectives, music educators have increasingly advocated for the adoption of student-centered approaches. These include open (Allsup, 2016), popular (Green, 2008), and democratic (Allsup, 2007; DeLorenzo, 2003; Draper, 2019; Woodford, 2005) pedagogies. Concert bands in particular have been targeted for reform (Allsup \& Benedict, 2008; Williams, 2011) because of their historical reliance on teacher-centric practices (Kratus, 2007). A democratic process wherein the teacher can scaffold experiences and facilitate learning may be more approachable for band directors than open, conductor-less, or popular approaches in order to provide increased studentcentered instruction.

Music education researchers have examined applications of democratic educational practices. Allsup (2003) and Swanson (2015) applied democratic principles in small-group settings focused on composition in instrumental and elementary classrooms. Allsup found that participants who worked democratically to compose music conceived of it "as fun....and personally meaningful" (p. 24). Both Swanson and Allsup noted that wide variation in student music ability and the use of specific student roles negatively affected the small-group learning process.

Implementation of democratic processes is reliant on teacher definitions and understandings (McNamara, 2019) and can be hindered by student resistance due to unfamiliar power structures (Giebelhausen \& Kruse, 2017; Silverman, 2013). Silverman (2013) conducted a critical ethnography of a music listening class that incorporated democratic educational processes including a reciprocal relationship between students and teacher. The unfamiliar power structure provided an initial challenge for students who were used to having content dictated; however, through the process, participants 
came to understand that the purpose was not to impose a strict understanding of music listening or value, but to cultivate democratic skills like critical thinking while engaging with music content.

Focusing on a conductor-less ensemble approach, researchers have explored the use of democratic educational principles within concert bands. In an examination of a collegiate concert band modeled on a conductor-less ensemble, Weidner (2019) identified three stages of ensemble interaction: (a) novice uncertainty, (b) individuals and basics, and (c) rule making and strategizing. In stage one, participants primarily used large runthroughs with little analysis resulting in slow progress. During stage two, individual leaders began to guide strategic discussion and specific musical phrases were addressed. However, ensemble members became visibly frustrated. The final stage was composed of developing formal roles, responsibilities, and policies legislating responsibilities. As students become familiar with the democratic rehearsal process, rehearsal strategies became more sophisticated and details beyond simple accuracy were rehearsed.

In a similar study of a collegiate concert band, Hedgecoth (2018) found that after an initial period of excitement, ensemble members' responses regarding whether they would want to repeat the experience were mixed. Participants described colleagues as dominating and controlling, likely referring to a subset of ensemble members who made $78 \%$ of all rehearsal comments. Regardless, $76 \%$ of ensemble members indicated they grew musically during the process and both ensemble and audience members expressed satisfaction with the final performance. Based on these findings, it seems possible to conclude that democratic practices may provide some musical benefit to large ensemble members. However, adopting a conductor-less approach for a single concert cycle may be 
impractical as the pressure to prepare for performance using an unfamiliar rehearsal process may negatively affect some ensemble members' experiences.

\section{Rationale}

Large performing ensembles have been characterized as autocratic and in need of reform (Allsup \& Benedict, 2008; Kratus, 2007 Williams, 2011). The application of democratic educational principles may be one way to provide a more participatory learning environment. Previous empirical investigations involving large performing ensembles have focused primarily on a conductor-less approach (Hedgecoth, 2018; Weidner, 2019). Therefore, the purpose of this study was to explore collegiate musicians' lived experiences with democratic rehearsal procedures using an embryonic approach in a concert band setting. I asked the following research questions: (a) What are participants' lived experiences with democratic rehearsal procedures during a concert band rehearsal cycle? (b) How is this experience similar or different from previous rehearsal experiences? and (c) How do previous experiences influence the present phenomenon?

\section{Method}

\section{Philosophical Worldview \& Theoretical Framework}

Social constructivism - sometimes referred to as interpretivism (Butler-Kisber, 2010; Mertens, 2010)—is a philosophical worldview through which "individuals seek understanding of the world in which they live and work" (Creswell, 2013, p. 24). It is guided by an understanding that multiple realities and subjective meanings exist. Therefore, analysis of individuals' complex and varied views must be undertaken through systematic procedures. I used a phenomenological framework to explore participants' experiences. The purpose of a phenomenological investigation is "to reduce individual 
experiences with a phenomenon to a description of the universal essence" (Creswell, 2013, p. 76). I adopted this worldview and framework as a way to explore how collegiate musicians experienced democratic rehearsal procedures in a concert band setting.

\section{Participants}

Members of a non-auditioned concert band at a large Midwestern university that I had co-directed for five semesters (including the semester during which data collection took place) were the participants for this study. All members of the ensemble $(N=42)-$ eleven $(26.19 \%)$ of whom had been members of the ensemble previously—elected to participate. Potential participants were read an IRB-approved (see Appendix A) verbal description and purpose statement of the study and were provided a consent form during the first rehearsal of the concert cycle (see Appendix B). Consent was indicated by completing the pre-rehearsal cycle questionnaire (see Appendix C) designed to gather data about participants' previous experiences with democratic rehearsal procedures in large performing ensemble settings and demographic information.

Participants identified as male $(n=14,33.33 \%)$ and female $(n=27,64.29 \%)$, with one individual who left this and other demographic questions blank. Their reported ages ranged from 18 to 21 years $(M=19.12, S D=1.29)$ and they had played their primary instrument for 5 to 13 years $(M=8.90, S D=2.01)$. Participants were non-music majors ( $n=37,88.10 \%)$, music education majors $(n=2,4.76 \%)$, and other music majors $(n=2,4.76 \%)$. Previous democratic rehearsal experiences were indicated by yes-no responses to eight prompts and one open-ended question. Participants indicated that "student-led sectionals" ( $n=38,90.48 \%)$, "providing feedback to their peers" $(n=35$, $83.33 \%)$, "identify and describe opportunities for performance improvement" $(n=32$, 
76.19\%), and "present, discuss, and make decisions regarding how the music should be performed" $(n=23,54.76 \%)$ were the most frequently previously experienced democratic rehearsal procedures. The least common experiences included "collaborative in-class score study" $(n=11,26.19 \%)$, "student-led full ensemble rehearsal" $(n=17$, $40.47 \%)$, "repertoire selection" ( $n=20,47.62 \%)$, and "identify and select music segments for rehearsal" $(n=21,50.00 \%)$. Responses to the open-ended question provided textual richness by allowing participants to express a general openness to further democratic experiences. For example, Colleen, a percussionist, wrote that "Previously I did not have much say in the rehearsal cycle apart from section rehearsals that I led or my individual solo. This makes me excited to try something new."

\section{Data Sources}

Multiple data sources were used to provide robust description of phenomena in this study. Sources included pre- and post-concert cycle questionnaires, weekly written reflections, transcripts of all rehearsal dialogue from each of the seven rehearsals, and transcripts from three individual interviews with a subset of five participants. With the exception of individual interviews, all data collection was completed during regular rehearsal times.

Weekly written reflections (see Appendix D) were completed after each Polly Oliver rehearsal segment. These allowed participants to (a) reflect on the effectiveness of each rehearsal, (b) provide suggestions regarding specific musical elements and rehearsal segments for future rehearsals, (c) consider the ways in which they contributed to the rehearsal, and (d) describe how they felt during the rehearsal process. 
Each rehearsal was video recorded using a Kodak Zi8 pocket video camera and audio recorded with a $H 2 n$ Handy Recorder. Both devices were positioned approximately 10 feet to the left of the conductor's podium facing the ensemble. I transcribed all conductor and student verbalizations from these rehearsal recordings to gather data about my interactions with the participants and their discussions with one another.

A series of semi-structured interviews with a purposively selected subset of participants was also used in this study (see Appendix E for a list of initial interview questions). In order to gather insight from a representative cross-section of the ensemble, participants who volunteered to be interviewed $(N=20)$ were grouped by instrument family (i.e., upper woodwinds, lower woodwinds, upper brass, low brass, and percussion) before being randomly selected. These five participants, one from each instrument family, completed three semi-structured interviews that ranged from 15 to 60 minutes each. Interviews were conducted after the third and sixth rehearsals and the final performance, and were used to collect perceptions of participants' experiences throughout the rehearsal cycle. I recorded interviews with the same audio and video devices used during each rehearsal and used the Otter app to record and transcribe interview audio.

The final data collection measure was a post-concert cycle questionnaire (see Appendix F) that was completed by participants on the evening of the final performance. This questionnaire was split into two sections so that participants had enough time to reflect on their final performance preparation and execution. Section one of the questionnaire prompted participants to reflect on the entire concert cycle, their experiences, strengths and weaknesses of the rehearsal procedures used, and beliefs about 
the efficacy of democratic rehearsals, and concluded with the opportunity to write any additional thoughts. This portion of the questionnaire was completed after the concert sound check that occurred one hour prior to the final performance. Immediately after their concert performance, participants completed the final section of the questionnaire which included one question about how successful they believed the performance was and another question about how the rehearsal process may have affected the final performance.

\section{Democratic Rehearsal Procedures}

I created a list of democratic rehearsal procedures to be used throughout the rehearsal cycle based on McNamara's (2019) concept of democratic musical voice and an embryonic democracy approach (Dewey, 1916; Woodford, 2005). In an embryonic democratic process, the teacher ensures that students are engaged with content at an educationally-appropriate level while allowing for more sophisticated involvement as they gain experience (Dewey, 1916; Woodford, 2005). Because an important part of developing musical voice was participants actively and directly engaging with the content, each other, and the conductor, both verbally and non-verbally (McNamara, 2019), I designed these procedures to ensure that ensemble members would have multiple means of engaging while using these procedures. Democratic rehearsal procedures included the ensemble members (a) collaborating in selecting music for performance, (b) participating in collaborative score study/preparation during rehearsal, (c) identifying and selecting music segments for rehearsal, (d) identifying and describing opportunities for individual and ensemble performance improvement, (e) analyzing, discussing, and 
making decisions regarding how the music should be performed, (f) participating in student-led sectionals, and (g) participating in student-led full ensemble rehearsal.

\section{Description of the Rehearsal Cycle}

Rehearsals were held on Tuesday evenings for two hours during the fall 2019 semester. During the eight-week concert cycle, 30-40 minutes of rehearsal time was allotted to the composition that was selected for use in this study. At the beginning of the second hour of the first rehearsal, participants selected the piece that was used for this investigation. Participants chose between Hypnotic Fireflies by Brian Balmages and Polly Oliver by Thomas Root. I had selected these pieces to present to the group because both were of comparable length (approximately 4 minutes) and grade difficulty (grade 3 and grade 2, respectively) according to the Teaching Music Through Performance in Band series. Both selections included extended periods of sustained chords, repetition of motives and themes, meter changes, several opportunities for expressive decisionmaking, and statements of original material that are varied, developed, and reprised. Participants were provided a researcher-constructed music selection sheet to take notes on the "structural, expressive, and technical elements" that they "appreciated" and "that the ensemble would need to focus on during rehearsals." This wording was used to encourage participants to think like expert conductors by considering the musical elements of each piece instead of reacting superficially.

Participants completed the music selection sheet while they listened to a model recording of each piece. After sight-reading each selection, they were given two minutes to write additional comments. Once this process was finished, participants discussed their repertoire preference based on the aforementioned characteristics with a nearby ensemble 
member for two minutes. After this time, the discussion continued for three minutes with the entire ensemble. Participants then voted for their preferred piece by raising their hands, with Polly Oliver being chosen by a vote of 23 to 17 (two members elected to abstain). Throughout the music repertoire selection process, I acted as the facilitator to ensure that all participants had the opportunity to present their ideas.

During rehearsals two through four, I acted as the lead facilitator. In this role, I selected rehearsal segments that would ensure the ensemble covered the entire piece during these three rehearsals. I began each rehearsal by outlining the rehearsal segment and highlighting participants' comments from the previous week's post-rehearsal reflections. At the beginning of rehearsal three, a collaborative score study session was included to help students think about how to lead a rehearsal using the same processes that would be used by an expert conductor. Throughout the rehearsal cycle, participants (a) identified and selected music segments for rehearsal; (b) identified and described opportunities for individual and ensemble performance improvement; and (c) analyzed, discussed, and made decisions regarding how the music should be performed. For students who may not have wanted to express their opinions in the large group setting, weekly post-rehearsal reflections provided another option to share their thoughts.

Having worked through the entire piece during the first half (i.e., weeks $1-4$ ) of the rehearsal cycle, I stepped back from my lead facilitator role during the fifth rehearsal to that of a moderator. I initiated the rehearsal as I had previously, but after a complete run-through of the piece, participants engaged in student-led sectionals. During this time, I moved between sections while acting as a resource and recording conversations for later transcription. The final two rehearsals (i.e., weeks 6 and 7) involved student-led full 
ensemble rehearsals. During these rehearsals, participants selected music elements to rehearse, rehearsal strategies to employ, and provided most of the feedback about their performance. I continued to act as a moderator by clarifying feedback and initiating rehearsal performances.

\section{Data Analysis}

I coded all documents using descriptive and in vivo coding to summarize the primary topic of each statement while using the participants' own words whenever possible (Saldaña, 2016). Next, I removed statements that did not relate to the research questions. I grouped the remaining statements based on themes that emerged from participants' descriptions and continued by clustering these themes to further illustrate participants' perceptions of the experience. Finally, a description of how the phenomenon was experienced by the participants was developed (Moustakas, 1994).

\section{Trustworthiness}

Trustworthiness was established through data triangulation, rich textual descriptions, peer review, bracketing to clarify researcher bias, and external review (Creswell, 2013). By collecting data from multiple sources (e.g., written reflections, interviews, and rehearsal transcripts), I was able to triangulate robust descriptions of participants' experiences using their own words. I also used peer review which involved discussing the progress of the study with a colleague in order to probe research biases and emergent themes (Creswell, 2013; Lincoln \& Guba, 1985). An external reviewer with experience conducting qualitative inquiries reviewed $20 \%$ of the data collected from each data source. After clarifying code descriptions (e.g., share an idea and provide feedback), 
an initial agreement of $78.04 \%$ was found. In order to reach $100 \%$ agreement, we discussed any discrepancies until consensus was achieved (Denzin \& Lincoln, 2005).

As one of the co-directors of the non-auditioned university concert band, I acted as the facilitator for these rehearsal experiences and also collected data for this study. Data collection took place between October and December 2019. I attempted to mitigate any possible conflicts of interest based on my relationship with participants as the codirector of this ensemble. Throughout the process, participants were reminded that their responses and participation in rehearsal discussion and reflective activities were not a graded portion of the course. Furthermore, reflective questions pertained to participants' experiences and not my teaching effectiveness nor the course structure. Because I had already been working with participants, a positive relationship had been established. As a result, I believe that I maintained an appropriate level of rapport throughout the data collection process.

\section{Epoché}

In a phenomenology, the researcher "set(s) aside their experiences as much as possible, to take a fresh perspective toward the phenomenon under examination" (Creswell, 2013, p. 80). To begin this process_ —often referred to as epoché or bracketing (Patton, 2015; Saldaña \& Omasta, 2018) - I wrote a reflection based upon my performing experiences in large ensemble rehearsals and discussed this reflection and my experiences with a doctoral student at my institution who also had several years of ensemble performance experience. This allowed me to identify biases related to my ensemble experiences, which I briefly describe here: 
I have been a member of large performing ensembles for over 20 years. For the vast majority of that time, the musical decisions were made from the podium and transmitted to myself and my colleagues. However, on occasion (i.e., an important solo line), musical decisions were made by the musicians. More frequently, musicians were allowed the opportunity to make decisions during chamber experiences incorporated within the large ensemble curriculum. As I matured as a musician, I found myself frustrated in rehearsals where my musical agency was minimized by mandates from the podium.

Although it is impossible to be completely unbiased, by examining one's own biases, one becomes more open to the experiences of others (Creswell, 2013; Moustakas, 1994).

\section{Findings}

Five themes emerged from the collegiate musicians' rehearsal experiences. Theme one, the value of multiple perspectives, referred to participants' desire to hear from and engage with peers who bring their own musical experiences and perspectives to each rehearsal. Ownership and musical agency, the second theme, related to music selection, agency within rehearsals, and feelings of accomplishment after the final performance. The third theme, active rehearsal engagement, was expressed by participants in both a direct and indirect fashion, but generally referred to feelings of active involvement during rehearsals. Providing feedback, the fourth theme, related to the kinds of feedback and rehearsal strategies used by participants as well as the potential challenges related to feelings of inadequate musical competency and familiarity with other ensemble members. The fifth theme, concerns with the amount of rehearsal time, 
reflected participants' unease with unfamiliar procedures and their worry that there would not be enough time to adequately prepare for their upcoming performance.

\section{Theme 1: The Value of Multiple Perspectives}

As collegiate musicians, participants recognized and appreciated each ensemble members' unique perspective based on their previous rehearsal experiences. During the second interview, Lyndsey ${ }^{1}$, a flute player, said, "It's really nice not only getting like one person being able to express their opinion, but also, you know, getting the feedback from everyone else." This sentiment was echoed by Sean, a saxophone player during his first interview:

I'm taking in what we can do differently with the music. When someone gives input or an opinion about what we should do with the music, I take that into consideration. It definitely makes me think differently about the music and it kind of puts on like a small challenge for me to see what I can do to make [the music] the best [I can] with that opinion.

Similarly, Alexis, a horn player, wrote in her week six rehearsal reflection that "Hearing from other people and sections helped me see issues I would not have noticed otherwise." Hearing from their peers provided the opportunity to think about how their part fit with other parts and what their colleague might be hearing or focusing on that led to their comment.

Multiple perspectives also provided an avenue for individual musical growth. In his second interview, Sean said:

\footnotetext{
${ }^{1}$ All names are pseudonyms
} 
I definitely think our musicianship is kind of increasing as we're having our own inputs on this. We're not listening to what just the band director wants, obviously, we're also listening to very specific details about the piece coming from different minds. [This provides insight into] how they are thinking about the music and everything. I definitely think it's really good to have something like that.

Alexis also felt that hearing from multiple people improved her musicianship. In her week six rehearsal reflection she wrote: "Student-led rehearsal brings more perspective which is always useful with musical interpretation." Similarly, during his third interview, Ben, a trombone player, said:

I think the difference is through the traditional method you learn, but you learn through one person. But with the democratic rehearsal you learn, but you get to learn through a bunch of different people. You get to learn a little bit and then you get to build on that.

\section{Theme 2: Ownership and Musical Agency}

Working together to learn and prepare the music provided participants with a sense of ownership and the opportunity to exercise their individual musical agency. In her final interview, Kinsey, a percussionist, stated:

We put in our own input and we got this all done and it sounded great. And I feel like realizing that you put in the input and stuff. You put in the work with the band. Just like how much more great you feel about it. You just feel like you actually did something to help with it.

Similarly, in his third interview, Sean said: 
It made me feel really good. It made me feel like I accomplished something bigger than what it seemed. If felt like, it felt like it was such a big performanceeven though it was the exact same as previous performances. It just felt more of a genuine thing [for] us. I think the best way to describe it is like when you buy something for yourself. You're going to find more value in it than when someone else buys it for you because you worked hard for it. You put more effort into the piece so you find more value [in the end]. You're getting a better reward [as opposed to] not being able to put your input in on a piece.

Other ensemble members mentioned this idea in their weekly reflections. Rick, a clarinetist, wrote, "I feel special and that my opinion on a piece matters" in his week four reflection. Another clarinetist writing in her week four reflection, Samantha, indicated that, "I think my input did contribute because we changed our style based on comments that Jessica and I made." Additionally, Jay, a trombone player, wrote that "it made me invest more in the music because rehearsal became what we made of it!" in his post-cycle questionnaire.

Participants exercised their musical agency through active participation in the rehearsal process with their peers. This required them to think deeply about the music and the perspectives their peers provided. Colleen, a percussionist, wrote the following in her post-cycle questionnaire:

We all feel more connected to the music. It's something we made ourselves rather than what we're playing being decided by someone else. We also learn more about the music-making process and can challenge ourselves to think more deeply and not just be robots. 
This idea of being more autonomous was echoed by Ben during his final interview:

But as it goes on and then you say, 'well, no, you're actually going to be contributing to this other than just playing the notes.' Like, you're no longer essentially a windup music box. You're actually going to be a musician. You're going to make your own choices and we're going to adapt to those depending on if the band thinks that that is the way to go.

\section{Theme 3: Active Rehearsal Engagement}

Participants indicated that they felt more engaged during rehearsal whether they were expressing their opinions verbally or responding to their peers. During his first interview, Ben observed, "It's interesting because...I'm a lot more focused on the song [and] I think I'm a little more tired by the time [the rehearsal segment] ends because I am so focused now." Lyndsey also felt an increased energy during rehearsals which she noted in her second interview:

Because people do have things they want to see get better. I know that I did...It was more engaging because other people were talking... Obviously everyone loves band and we were listening to the directors, we know what to do, but when you switch things up a little bit and you get to hear from different voices, it's more of an active experience in general...Listening around the room [and] hearing what other people had to say is just more of an active atmosphere...I just kind of felt like our rehearsals go by more quickly when we were doing the democratic thing. And I think this just comes down to the psychology of being more engaged when there are more things to pay attention to...It's literally kind of like the time flies when you have fun kind of thing. 
Participants felt like they were actively involved in the rehearsal process. In her postcycle questionnaire, Allison, a flute player, wrote, "I always felt like I played an active role in the rehearsal process" in her post-cycle questionnaire. During his final interview, Sean stated:

I definitely enjoy the democratic rehearsals more in the sense of just the involvement. The fact that more students can put their input on the piece and think about more of what we can do instead of just listening to what the director wants...I definitely liked it. I like the involvement that everyone gets to have.

\section{Theme 4: Providing Feedback}

In order for democratic rehearsals to work as intended, participants had to provide feedback. Musical elements addressed through feedback ranged widely from specific technical elements (e.g., notes, rhythms, and tuning) to broader concepts (i.e., phrase shaping). Initially, many of the comments included broad ideas about phrasing and dynamics, but as the rehearsal cycle progressed, comments became increasingly specific and participants became more tenacious by asking the ensemble to repeat things multiple times until the desired musical effect was achieved.

During the initial rehearsals, participants felt hesitant or unsure when provided opportunities to provide feedback. In her first interview, Lyndsey said, "I think we were a little bit shy at first, but now it's kind of inviting the more engaged and active listening." Maureen, a horn player, attributed a hesitancy to provide feedback to nerves related to unfamiliar procedures and ensemble members during her first interview: "I think that's just nerves. I think everybody has an opinion on what needs to be worked on...A lot of us don't know each other. Just being afraid to speak up...I think we are all just a bit 
nervous." Similarly, in her first interview Kinsey stated, “I just don't want to be wrong, I guess. I don't really know people in the band as much."

Unfamiliarity with ensemble members was not participants' only concern when providing feedback. Participants were also aware that they were not experts. During her first interview, Maureen said, “I didn’t play French horn for three years and I started again this year. As I got more comfortable with my instrument, I got more comfortable sharing my opinion with the band as a whole." Reflecting on the process in her final interview, Kinsey said:

It kind of was a little harder to put in feedback than like working at sectionals. Being with your own group, your own instruments, it's just easier I guess to discuss what you need to work on. But like I said previously, it's just harder to mention things with the whole band.

A final concern regarding providing feedback was related to an understanding of a democratic process. Participants were cognizant of ideas related to fairness and didn't want to become overbearing. During her first interview, Lyndsey said, "Nobody wants to be the person that talks for too long and everyone's like, 'why are you talking?"' Similarly, in his second interview, Ben stated:

I tell you that I can sometimes wrestle with this idea of like, you know, have I talked too much today? ... I don't want to be the guy who entices other people to not speak up because they know I'm going to say something ... I want to hear what someone else thinks about this because if it's just me contributing, then I'm essentially the new band director. 


\section{Theme 5: Concerns with the Amount of Rehearsal Time}

Time and the relation that it could have on incorporating democratic rehearsal procedures was an underlying concern for many participants. In his pre-rehearsal questionnaire, Nathan wrote that "[democratic rehearsals] can take much longer than if one person were doing it." Similarly, Mike wrote that "we don't have enough time to use democratic procedures in this ensemble. We only have 2 hours of rehearsal once per week." in his pre-cycle questionnaire. Reflecting on the first few rehearsals in her second interview, Maureen stated, "It is certainly more time consuming to practice Polly Oliver." And later in the same interview she mentioned that "I think that if we spend more time as an ensemble together, like for instance if it was a high school band where almost everyone knows each other, I think that it will go a bit more quickly.” In the postrehearsal cycle questionnaire, all participants who responded to a question about the success of the performance $(n=39)$ indicated that the performance was good. Additionally, a large majority thought large ensembles should be more democratic $(n=$ $22,78.57 \%)^{2}$ suggesting that they would look forward to rehearsing using democratic rehearsal procedures in the future. However, not all participants agreed. For example, Lacy wrote that she would not look forward to future democratic rehearsals because she felt that "[rehearsing democratically] took up too much time." in her post-cycle questionnaire.

\section{Essence}

I investigated collegiate musicians' experiences with an embryonic democratic rehearsal procedure during an 8-week concert cycle in a non-auditioned concert band.

\footnotetext{
${ }^{2}$ Not all participants responded to this question, $N=28$
} 
Participants indicated that the experience was largely positive, that they valued their fellow musicians' perspectives and past musical experiences, and that being provided an opportunity to exercise their musical agency encouraged active engagement and a sense of ownership. Challenges related to knowledge of content, familiarity with other ensemble members, and the time required to rehearse democratically were obstacles that affected individuals' ability to provide verbal feedback to the entire ensemble. Participants believed that the final performance was successful and most indicated that large ensembles should be more democratic.

\section{Discussion}

Participants valued hearing their peers' comments because each possessed a unique perspective. Hearing from other ensemble members helped participants to think differently about the music because they considered ways to reconcile their interpretation with their colleagues. Although ensemble members might undergo a similar process in a teacher-centric rehearsal, participants indicated that getting lots of different viewpoints was more beneficial because they engaged in more critical thinking when the comments were not from the conductor exclusively. Consonant with a previous investigation of a democratic collegiate rehearsal experience (Hedgecoth, 2018), some participants indicated that the process of engaging in more active critical thinking during rehearsal improved their musicianship. Providing ensemble members the opportunity to actively discuss and reconcile music interpretation allows band directors to assess their students' musical understanding and thinking and modify instruction. A better understanding of the effects of a democratic discussion-based rehearsal on music comprehension or 
performance outcomes might prove valuable to music educators and music teacher educators interested in developing students' musicianship and musical independence.

Collegiate musicians in this study described being more engaged during democratic rehearsals than past teacher-centric rehearsals. Their engagement related to McNamara's (2019) concept of musical voice, in which participants could share an idea verbally or simply respond musically to colleagues' suggestions. However, whether they shared verbally or not, participants indicated that they were engaged in making musical decisions. Research regarding the kinds of engagement ensemble members exhibit and for what length of time in both conductor-less and teacher-facilitated democratic rehearsals might help us to understand the practicality of democratic rehearsals from an engagement standpoint and how the teacher can affect that process positively.

Providing feedback and engaging in discussion is essential for democratic rehearsals. Consonant with previous investigations of collegiate ensembles that used democratic practices (Weidner, 2019), participants' feedback in the present study became increasingly specific and performance expectations more tenacious as the rehearsal cycle progressed. Based on these findings, it seems likely that after an initial period of learning to rehearse democratically, students with previously limited democratic experiences could be expected to engage effectively in democratic rehearsals. Longitudinal studies might provide a valuable understanding of how students' expectations and their commentary in rehearsal might evolve over several concert cycles.

Although participants were able to engage in democratic rehearsals by providing feedback, some participants indicated feeling hesitant about providing verbal suggestions to their peers. This hesitation was often linked to (a) feelings of musical insecurity, (b) 
unfamiliarity with ensemble members, and (c) concern about being over-bearing. These concerns may have related to a lack of strong relationships with other ensemble members. Collegiate ensembles differ from many high school counterparts in that the personnel change more frequently. Perhaps a certain level of community building is necessary for more ensemble members to feel comfortable sharing during rehearsals. Researchers could investigate how community relationships affect democratic experiences in concert bands.

Consonant with investigations in general education settings (Brelias, 2015;

Hauver, 2017; Helwig, 1998; McAvoy \& Hess, 2013), participants' concerns about being over-bearing may have indicated an understanding that fairness and providing opportunities to share is important. Hedgecoth (2018) found that when a small subset of ensemble members provided the vast majority of comments positive feelings toward democratic rehearsals were reduced. Although leadership roles develop in even the most democratic organizations, future investigators could examine what characteristics might predict leadership roles in democratic ensembles and the efficacy of such leadership.

Feeling like there was not going to be enough time was a common concern for participants in this study. This may have been a reaction to an unfamiliar rehearsal process, which is consonant with findings from previous investigations using democratic practices (Giebelhausen \& Kruse, 2017; Silverman, 2013). The relative unfamiliarity of ensemble members - in comparison to a school cohort that advances together for many years - and fear of being wrong were two concerns that affected participants' decisions to provide verbal feedback during rehearsal. Even with these challenges, by the end of the concert cycle, participants agreed that the performance was successful, and many indicated feeling a sense of personal accomplishment. There is always a finite amount of 
rehearsal time in any concert cycle. Future researchers might investigate time usage in democratic and teacher-centric rehearsals and to what extent ensemble size and members' previous experiences with democratic experiences affect the rehearsal process.

I investigated the lived experiences of 42 collegiate musicians with an embryonic democratic rehearsal process. Generalization of these experiences must be done with caution as every democratic experience will be different based on the members' past experiences and the community dynamics of each individual ensemble. Additionally, the participants in this investigation had several years of musical experiences to draw from when formulating rehearsal feedback. It seems likely that younger students may require more help when first being introduced to democratic experiences than the participants of this investigation. Finally, generalizations to other historically teacher-centric large performing ensembles (i.e., choirs and orchestras) should be done carefully as rehearsal practices vary between these large ensembles and their directors.

\section{Conclusion}

Participants in this study indicated that an embryonic democratic rehearsal cycle was a generally positive experience. Feelings like engagement and ownership developed through opportunities for increased student agency and an appreciation of peer perspectives. Regular use of democratic rehearsal procedures, after a scaffolded introduction, could be a valuable way for large ensemble directors to shift some rehearsal responsibility to their students. Doing so may aid students' musical growth and might be beneficial for the development of musical independence. More advanced ensembles or groups with lots of democratic experiences might benefit from open, student-led rehearsals even earlier in a concert cycle than what was used in this investigation. 
Additional research is needed to understand how large ensembles that already include democratic processes could enculturate new members. Regardless, the role of the teacher shifts from sole purveyor of knowledge and interpreter to facilitator, guiding rehearsal experiences so that students can continue to take increased responsibility in music preparation and performance.

The teacher can also play a critical role during democratic rehearsals. Concerns related to non-dominant perspectives being limited (Gould, 2007, 2008) can be mitigated by a creative director. In the present study, weekly written reflections allowed me to gain insight into each ensemble members' perspective. During early rehearsals these perspectives were shared by me as a means of initiating discussion and encouraging hesitant students to feel comfortable sharing verbally during rehearsal. Teachers with access to reliable classroom technology could also consider using software that included instant polls or short answer questions that could be analyzed in real time and used later to demonstrate student learning. Finally, by actively adopting a reciprocal relationship, teachers can support skillful learning (Allsup, 2007) by being valuable models, clarifying student meanings, and assisting in resolving conflict.

Although the role of the democratic director differs from traditional models, adopting an embryonic approach allows the director and their students to negotiate new roles and responsibilities. I encourage large ensemble instructors to regularly include democratic rehearsal procedures in their instruction. As teachers and students become more comfortable with new and modified classroom dynamics, directors might consider using democratic procedures with one piece for an upcoming concert, similar to what occurred in the present study. Festivals and other competitions are part of the regular 
schedule of most large ensembles. Although collegiate musicians have been successful in preparing for performance using conductor-less models (Hedgecoth, 2018), directors may not be willing to cede control because contest and festival ratings are often equated with program success. These rehearsal cycles may not function well when choosing to adopt a large-scale democratic rehearsal process; however, regular incorporation of democratic procedures may aid in maintaining student engagement and ownership. Democratic rehearsal procedures are a valuable opportunity for large ensemble directors to engage students in the same processes that accomplished musicians use regularly. Preparing student musicians for these experiences requires modifying traditional roles; however, even minimal implementation may increase student engagement, ownership, and leadership while improving the classroom environment and developing individuals' musical independence. 


\section{Chapter Four}

\section{High School Band Directors' Perceptions and Applications of Democratic Rehearsal Procedures in Concert Band Rehearsals}

Curricular initiatives like the National Core Arts Standards (NCAS) (National Coalition for Core Arts Standards [NCCAS], 2014) have spurred appeals from within the music education community for large ensemble instructors to include opportunities for students beyond performance. In response to the NCAS, several student-centered teaching approaches have emerged. Popular (Green, 2008) and open (Allsup, 2016) pedagogies emphasize student discovery and choice, but do so by reducing the role of the teacher. Critical (Schmidt, 2005) and democratic (Tan, 2014; Woodford, 2005) approaches consist of collaborative processes that include the teacher, making them more accessible for performing ensembles that have historically featured a teacher-centric model.

Although a strong relationship exists between democratic and critical pedagogies, democratic practices may be easier to implement in large ensemble settings. In a democratic classroom, students and the teacher actively collaborate with each other through discussion and consensus building (Dewey, 1916). The teacher is an important part of the classroom by participating in discussion, ensuring discourse is nonrepressive and nondiscriminatory (Gutmann, 1987/1999), and scaffolding experiences based on student ability (Dewey, 1916; Woodford, 2005). A teacher who adopts critical pedagogy might incorporate similar learning processes; however, an emphasis on examining status quo conceptions may considerably reduce rehearsal time and lead to content that is more closely related to popular pedagogy. 
Applications of democratic practices have been investigated in public school settings. Large-scale implementation (i.e., school or program-wide adoption) has been credited with improved positive attitudes toward school (Cleaver \& Riddle, 2014) and findings from classroom investigations have indicated improved critical thinking skills (Brown, 2012), a sense of openness (McAvoy \& Hess, 2013; Pennisi, 2013), and increased student agency (Boatright \& Allman, 2018). Although children as young as nine have successfully participated in democratic discussions (Hauver, 2017), implementation required careful planning as all students may not feel comfortable participating (Hemmings, 2000). Additionally, teachers must consider how to prepare students to engage in conversations that are fair and acknowledge privilege (Brelias, 2015; Helwig, 1998). Although adopting a democratic process changes the format and power structure of the classroom, educators have expressed appreciation for the reciprocal relationship that doing so created and the empowerment that it provided students (Collins et al., 2019).

Concert band directors are often targeted for not evolving with current educational practices (Allsup \& Benedict, 2008; Williams, 2011) because they are perceived as relying on historically teacher-centric ensemble rehearsal models (Kratus, 2007). Pre-service teachers are influenced by their early collegiate experiences and models such as performing ensembles and applied lessons (Bauer \& Berg, 2001) and student teaching experiences (Conway, 2002), all of which largely remain teachercentric. Additionally, competition in music is an influential reality for many band directors who hesitate to cede control because of potential effects on large ensemble festival ratings (Rohrer, 2002). Because large performing ensembles-like concert 
bands - serve as the primary source of music education at the secondary level in the United States (Elpus \& Abril, 2019), it seems important to investigate how democratic practices may be applied in this setting.

Despite the widespread use of teacher-centric models, many music educators have suggested adopting democratic educational practices in music classrooms. Applying democratic practices in a middle school music program, Draper (2019) described the experience as exciting and challenging for the teacher. She also found that students were more motivated and became increasingly independent. DeLorenzo (2003) advocated for applying democratic practices through (a) structuring classrooms to promote fairness, trust, and respect; (b) incorporating critical thinking in music structures, content, and repertoire choices; and (c) developing student leadership skills to advocate for social justice in the classroom and community. In addressing common challenges related to democratic education, Allsup (2007) proposed that the biggest barrier to application was music educators' emphasis on technical skill acquisition and the methods used to teach these skills. To combat these issues, Allsup suggested adopting a reciprocal relationship focused on creating skillful individuals. Gould (2008) challenged democratic educators to reflect on their understanding of democracy and ensure that non-dominant viewpoints were actively included in classroom discussion so that consensus building would not be limited only to one or two perspectives. Although not specifically democratic, recent interest in experiential ensembles closely relates to democratic practices by encouraging students to develop their musical agency and independence (Marcetti, 2019) and further demonstrates interest in a more democratic and open music teaching and learning approach for large ensembles. 
Democratic educational practices have also been investigated in music education settings. Silverman (2013) applied democratic principles in a music listening course by engaging participants in the music repertoire selection process. Unfamiliar with the modified power structure, participants initially resisted, but at the end of the experience acknowledged that selecting music encouraged the development of critical reflection and analysis skills. Democratic practices have also been applied in small composition units. Allsup (2003) found that secondary students enjoyed working together democratically and students described the experience as meaningful. Working with elementary students, Swanson (2015) found that democratic practices allowed students to work together collaboratively, but that wide variation in skill within groups posed challenges that reduced complete engagement in the process. Based on the findings of these studies, perhaps democratic practices can be useful tools across a wide range of age levels and music content areas.

Although democratic practices may be valuable in music classrooms, investigations of large ensemble directors who have incorporated these principles remains limited. Examining democratic processes in a conductor-less collegiate concert band, Weidner (2019) identified three stages of ensemble interaction: (a) novice uncertainty, (b) individuals and basics, and (c) rule making and strategizing. As participants progressed through these stages, participant roles and rehearsal practices became increasingly sophisticated, leading to the establishment of formal roles and responsibilities. Hedgecoth (2018) also investigated a conductor-less collegiate concert band and found that a subset of members made $78 \%$ of all rehearsal comments, resulting in a process that was less democratic than many participants had initially hoped. However, ensemble members 
were able to successfully prepare music for performance at a state music education conference and $76 \%$ of participants indicated feeling like they grew musically through the process. Potential benefits like empowerment, engagement, agency, independence, and growth in content knowledge present in other investigations may also apply within large ensembles; however, additional investigations are needed to better understand the effects of implementation on students' attitudes and ensemble performance outcomes.

For democratic principles to be applied in any classroom, the teacher must make the decision to initiate the process. McNamara (2019) conducted a national survey of K12 music teachers' attitudes and behaviors toward democratic teaching practices.

Findings indicated that educators frequently described democratic practices as a means of developing student agency and independence and held generally positive attitudes toward democratic practices that provided opportunities to apply agency and independence through musical choice. However, educators' applications of democratic practices, like collaborative discussion within class, were limited and time was identified as the biggest barrier for implementation. In another study from his dissertation, McNamara (2019) investigated two self-identified democratic educators who taught collegiate instrumental music education coursework. He found that teachers' definitions of democracy influenced the kinds of activities they provided their students. However, although definitions varied, both educators examined in his study adopted a scaffolded approach by organizing activities that incrementally increased opportunities for student agency.

Although interest in democratic processes has increased within the music education community (Allsup, 2003, 2007; DeLorenzo, 2003; Draper, 2019), concert band directors' beliefs and applications of these practices remain under investigated. 
Concert bands are frequently identified as ensemble experiences that are in need of educational reform (Allsup \& Benedict, 2008; Kratus, 2007; Williams, 2011). Previous investigations involving concert bands have focused on a conductor-less model applied at the collegiate level (Hedgecoth, 2018; Weidner, 2019), but it is not known how in-service high school band directors view, adopt, or adapt democratic practices. Understanding inservice high school band directors' attitudes and applications of democratic rehearsal procedures will provide valuable insight for music teacher educators as they prepare preservice instrumental music teachers who may be expected to provide students with more than a performance-only ensemble experience.

The purpose of this study was to examine in-service high school band directors' perceptions and applications of democratic rehearsal procedures in concert band rehearsals. The research questions were: (1) How important do high school band directors believe it is for students to engage in democratic rehearsal procedures? (2) How frequently do high school band directors incorporate various democratic rehearsal procedures within their concert band rehearsals? and (3) What perceived advantages and disadvantages exist when applying democratic rehearsal procedures?

\section{Method}

I recruited NAfME members who were in-service high school (teaching some combination of students that included grades 9-12) concert band directors to participate in this survey study. After I received approval from the Society for Research in Music Education (SRME) Executive Committee and paid a distribution fee, an assistant at NAfME distributed an electronic email invitation to 9,748 high school band directors on my behalf. This message included IRB-approved consent information, the purpose 
statement, a brief description of the study, and an electronic link to the survey (see Appendix G). Of the sent messages, a total of 7,112 (72.96\%) emails were not opened. This resulted in 2,636 (27.04\%) emails that were received and opened. A reminder email was sent one week after the initial distribution. The first page of the questionnaire served as the consent form and included a detailed description of the study, the purpose/rationale, and IRB and researcher contact information. The second page of the questionnaire provided respondents the opportunity to confirm that they were current high school band directors. A total of 338 (12.82\%) of the 2,636 individuals who opened the message responded to the survey. However, thirty-six respondents indicated that they were not high school band directors and an additional 49 respondents did not proceed beyond question one. After removing these individuals' responses, a total of $216(8.19 \%)$ acceptable responses remained.

\section{Survey Construction}

To construct the survey, I began by creating a list of democratic rehearsal procedures based on the concepts of embryonic democracy and "musical voice." Embryonic democracy is the process of gradually providing students with increasingly sophisticated means of interacting with each other as their cognitive abilities, content knowledge, and experience in a democratic environment increase (Dewey, 1916; Woodford, 2005). Therefore, I selected techniques that afforded students a range of interaction based on their abilities. Furthermore, I included prompts that were both familiar (e.g., student-led sectionals) and unfamiliar (e.g., student-led full ensemble rehearsal) for in-service band directors. Regardless of the degree of sophistication involved in peer-to-peer and student-to-teacher interaction, each democratic rehearsal 
procedure provided students the opportunity to develop their "musical voice" through making the same kinds of decisions that musicians make in response to their own conceptions of sound and the music being played (McNamara, 2019).

Given these ideas, I created the following list of democratic rehearsal procedures: (a) select music for performance, (b) in-class collaborative score study/preparation, (c) identify and select segments for rehearsal, (d) identify and describe opportunities for individual and ensemble performance improvement, (e) analyze, discuss, and make decisions regarding how the music should be performed, (f) student-led sectionals, and (g) student-led full ensemble rehearsal. In addition, respondents were asked to add any other rehearsal procedures that they identified as democratic and used as part of their large ensemble teaching process.

I used Qualtrics, an online survey program, to create and distribute the IRBapproved (see Appendix H) questionnaire for this study. The survey consisted of three sections designed to gather information about in-service band directors' (a) perceptions of democratic rehearsal procedures (7 items), (b) application of democratic rehearsal procedures ( 7 items), and (c) experiences (both positive and negative) when applying democratic procedures ( 2 questions) (see Appendix I). To establish content validity, six music teacher educators who had previously either published peer-reviewed articles or presented on ideas related to democratic music education were asked to review the survey items. Based on their recommendations, two additional demographic questions were added and one democratic rehearsal procedure prompt was removed. After making these changes, I asked five in-service high school concert band directors to pilot test the survey to receive feedback on the clarity and time required to complete. Based on pilot testers' 
feedback, minor wording changes to two prompts were made. I chose not to examine statistical indicators of reliability because I felt that respondents would respond truthfully. This decision was consistent with authors of recent studies who also reported respondents' beliefs about their own personal behaviors and did not report measures of reliability (Egger \& Springer, 2018; Silvey et al., 2016; Sims \& Cassidy, 2015).

The survey, which took approximately 10 minutes to complete, included Likerttype scale and open-ended response questions. After completing these sections of the survey, respondents listed any sources or experiences regarding how they had learned about democratic rehearsal procedures and completed a demographic questionnaire.

\section{Participants}

Respondents $(N=216)$ identified as male $(n=128,59.26 \%)$, female $(n=53$, $24.54 \%)$, non-binary/third gender $(n=1,0.46 \%)$, or indicated that they preferred not to answer $(n=4,1.85 \%)$. Additionally, thirty respondents left this and other demographic questions blank. Their reported ages ranged from 22 to 67 years $(M=43.05, S D=11.06)$. All but one respondent had completed their bachelor's degree and more than half of participants had completed graduate degrees (master's, $n=128$; doctorate, $n=7$ ). Areas of graduate study included music education ( $n=65)$, conducting $(n=27)$, music performance $(n=11)$, music therapy $(n=1)$, jazz studies $(n=1)$, music theory or composition $(n=3)$, and other areas of study $(n=28)$ such as education leadership, special education, and administration.

Respondents reported their years of experience teaching high school concert band $(M=16.17, S D=10.34)$, with a range of 1 to 56 years, and the number of years teaching at their current school ( $M=10.61, S D=8.04,1$ to 36 year range). Most respondents self- 
identified their school as suburban $(n=87,40.28 \%)$, whereas others indicated that they taught in rural $(n=67,31.02 \%)$ and urban schools $(n=29,13.42 \%)$. Respondents reported that the size of their high school band programs ranged from 8 to 450 students $(M=101.85, S D=81.97)$ and the size of their average concert band consisted of 9 to 105 members $(M=46.31, S D=20.40)$. All six NAfME regions (North Central region $(n=52$, $24.07 \%)$, Southern region $(n=38,17.59 \%)$, Southwestern region $(n=29,13.43 \%)$, Eastern region $(n=26,12.04 \%)$, Western region $(n=22,10.19 \%)$, and Northwest region $(n=16,7.41 \%))$ were represented.

\section{Results}

\section{Beliefs About the Importance of Democratic Rehearsal Experiences}

The first section of the survey collected respondents' beliefs about how important it was for students to experience democratic rehearsal procedures. Respondents were asked to "rate how important you believe it is that band students experience each of the following democratic rehearsal procedures during an academic year while in high school concert band." Respondents provided answers to the seven prompts (e.g., select music for performance, identify and describe opportunities for individual and ensemble performance improvement, and student-led sectionals) using a Likert-type scale anchored by 1 (not at all important) and 5 (very important).

Band directors' mean ratings for the importance of students experiencing democratic rehearsal procedures were generally high with "identify and describe opportunities for individual and ensemble performance improvement" and "student-led sectionals" rated highest $(M=4.28, S D=0.86$ and $M=4.12, S D=0.95$, respectively). This was followed by "analyze, discuss, and make decisions regarding how the music 
should be performed" $(M=3.83, S D=1.01)$ and "identify and select music segments for rehearsal" $(M=3.52, S D=1.13)$. Receiving the lowest ratings were "student-led full ensemble rehearsal" $(M=2.64, S D=1.08)$, "select music for performance" $(M=3.03$, $S D=1.02)$, and "in-class collaborative score study/preparation" $(M=3.05, S D=1.11)$.

\section{Frequency of Application of Democratic Rehearsal Procedures}

The second section of the survey was focused on respondents' self-reported use of democratic rehearsal procedures. Respondents were asked to "rate how frequently your students experience each of the following democratic rehearsal procedures during a typical concert band rehearsal cycle." Respondents provided answers using a Likert-type scale anchored by 1 (never) and 5 (almost always). The highest-rated activities were “identify and describe opportunities for individual and ensemble performance improvement," "student-led sectionals," and "analyze, discuss, and make decisions regarding how the music should be performed" $(M=3.80, S D=1.00 ; M=3.49, S D=$ 1.12 ; and $M=3.39, S D=0.98$, respectively). The lowest-rated activities were "studentled full ensemble rehearsals," "in-class collaborative score study/preparation," and "select music for performance" $(M=2.09, S D=0.91 ; M=2.36, S D=1.05$; and $M=$ $2.80, S D=0.93$, respectively). Descriptive statistics for all items in the first two sections of the survey are presented in Table 1 . 


\section{Table 1}

Means and Standard Deviations of Democratic Rehearsal Procedures

\begin{tabular}{lcccc}
\hline Variable & \multicolumn{2}{c}{ Importance $^{\mathrm{a}}$} & \multicolumn{2}{c}{ Frequency $^{\mathrm{b}}$} \\
\cline { 2 - 5 } & $M$ & $S D$ & $M$ & $S D$ \\
\hline Identify and describe opportunities for individual & 4.28 & 0.86 & 3.80 & 1.00 \\
$\quad$ & & & & \\
$\quad$ and ensemble performance improvement & 4.12 & 0.95 & 3.49 & 1.12 \\
$\quad$ Student-led sectionals & 3.83 & 1.01 & 3.39 & 0.98 \\
Analyze, discuss, and make decisions regarding & & & & \\
$\quad$ how the music should be performed & 3.52 & 1.13 & 3.15 & 0.98 \\
$\quad$ Identify and select music segments for rehearsal & 3.05 & 1.11 & 2.36 & 1.05 \\
In-class collaborative score study/preparation & 3.03 & 1.02 & 2.80 & 0.93 \\
Select music for performance & 2.64 & 1.08 & 2.09 & 0.91 \\
Student-led full ensemble rehearsals & & & & \\
\hline
\end{tabular}

${ }^{\mathrm{a}}$ Importance responses were rated on a scale of 1 (not at all important) to 5 (very important). ${ }^{\mathrm{b}}$ Frequency responses were rated on a scale of 1 (never) to 5 (almost always).

\section{Perceptions of Advantages and Disadvantages of Democratic Rehearsal Procedures}

In the third section of the survey, respondents answered open-ended questions about perceived advantages and disadvantages related to implementing democratic rehearsal procedures. I analyzed and coded individual responses using an open coding procedure with descriptive and in vivo coding (Saldaña, 2016). A reliability coder familiar with qualitative research coded $20 \%$ of the data, resulting in $73.35 \%$ agreement. We met and discussed our coding and themes until any disagreements were resolved and $100 \%$ consensus was achieved (Denzin \& Lincoln, 2005). 


\section{Advantages}

Analysis of comments related to the advantages of including democratic rehearsal procedures resulted in four themes: (a) student ownership $(n=68,45.03 \%)$, (b) student engagement ( $n=33,21.85 \%)$, (c) student growth as musicians and leaders $(n=31$, $20.53 \%)$, and (d) the value of multiple perspectives $(n=4,2.65 \%)$. Fifteen other comments $(9.94 \%)$ were unrelated to these four themes, resulting in a total of 151 comments. (Not all respondents provided comments, whereas others wrote multiple comments.)

The most frequently cited advantage was student ownership. Comments such as "students become more invested in the rehearsal process and take ownership over the music they are rehearsing" were common. Similarly, respondents indicated that ownership extended to the ensemble: "makes the students take ownership of the group as a whole." For one respondent, student ownership increased trust between the teacher and students: "They take greater ownership of their music when they had a choice of what to play (even though I was the one who picked all the options that they chose from). When I am gone, I can leave sub plans that say, 'This class can run themselves. Tell them to do and I know that it will get done."

Respondents indicated that they believed student engagement was one advantage of implementing democratic rehearsal procedures. For example, one respondent wrote "Increased student engagement. Students gain experience with the creative processes of music. Greater understanding of the connection between their part and the whole. Better questions. More active listening. A deeper sense of meaning taken from the rehearsal process." Another respondent added that although engagement was an advantage, a 
certain amount of preparation and practice was required before peak engagement and efficiency was met: "When the ensemble reaches the level of productive input, their engagement and buy-in to the music greatly increases. Students always want their opinion to be valued and this creates a space where they can be creative and have discussions that go beyond just the director dictating what is happening in the classroom."

Band directors' responses indicated that democratic rehearsal procedures encouraged students' musical growth and leadership. One respondent wrote:

I LOVE when a student voices their opinion on how something should be performed or how something could be improved. Students sometimes start playing devil's advocate and try to look at things from all angles which encourages the artistic decision-making that we face as musicians. Usually, we try multiple methods (even if I know it is the wrong way to interpret something) just so they can go through the decision-making process. After all, it's these decisions that actually teach artistry. Without them, we are just training robots. (emphasis in original)

According to some respondents, sectionals were considered a primary opportunity for students to develop leadership skills. However, other practices that emphasized student agency also contributed to increased student leadership: "It builds intrinsic motivation, student leadership, and puts the responsibility on the students. Sometimes students get frustrated because I ask them what we need to do instead of just telling them."

Finally, respondents indicated that students and teachers benefited from engaging with multiple perspectives during rehearsal. One respondent wrote, "it is useful to know 
what the students are hearing from their placement in the ensemble." Another indicated that "all students gain knowledge via different delivery approaches."

\section{Disadvantages}

Four themes emerged from responses related to disadvantages: (a) issues related to students' ability ( $n=73,42.94 \%)$, (b) rehearsal time limitations ( $n=45,26.47 \%)$, (c) unfamiliar classroom dynamics ( $n=17,10.00 \%)$, and (d) availability of classroom resources $(n=14,8.23 \%)$. Twenty-one other comments $(12.35 \%)$ were unrelated to these four themes, resulting in a total of 170 comments. (Not all respondents wrote comments, whereas others included multiple comments.)

Comments relating to students' lack of content and procedural knowledge such as "students do not have the skills to identify the intricacies of what we need to correct..." and "the biggest limitation is that none of my students have a four-year degree, master's degree, and more than 60 credits beyond a master's [degree]. They're students, not teachers" were typical. Additionally, some of the comments were specific to students' perceived inability to select repertoire. Some examples included "they usually picked music that they like the first rehearsal because it is easy..." and "students would rather play pep band music all the time. They do not have the training nor maturity to make an informed decision."

Responses pertaining to rehearsal time constraints were also common. For example, one respondent wrote "Time! With a full performance schedule, items like these take time to implement in an orderly fashion." Other respondents identified short class times "Only so much time in a rehearsal, 45 minutes is not enough as it is" and the 
possibility that democratic rehearsal can "sometimes lead to less literature being performed" as limitations of democratic procedures.

Changing classroom dynamics due to increased student agency were also a concern. Respondents indicated that preparing students for increased responsibility required extra preparation and time: "Students who are in leadership roles must be taught how to make these practices work. These democratic processes work well when you take the time to teach the process. If not, it creates a certain amount of bad chaos as opposed to good chaos." One respondent identified themselves as a limiting influence in writing that "I simply have a hard time letting go. I think I am the limitation." This may indicate that unfamiliar classroom rehearsal procedures may be challenging for both students and teachers.

Challenges related to the availability of classroom resources included issues relating to rehearsal time and space. A few respondents noted that their facilities were not conducive to certain procedures (i.e., sectionals) due to limited space. For example, "there is not sufficient space to break into sectionals during class." One respondent indicated that technology was also a limiting issue by responding that "I wish I had a better way to show students the score. Our projector is not positioned well in the room."

\section{Discussion}

The purpose of this study was to examine in-service high school band directors' perceptions and applications of democratic rehearsal procedures in concert band rehearsals. Although music educators have expressed interest in democratic education (Allsup, 2003, 2007; DeLorenzo, 2003; Draper, 2019) and researchers have examined K12 educators' attitudes and beliefs toward democratic educational principles (McNamara, 
2019), little extant data exists concerning concert band directors' beliefs and applications of democratic rehearsal procedures. I gathered information about their (a) beliefs regarding the importance for students to engage in democratic rehearsal procedures, (b) how frequently they incorporated democratic rehearsal procedures within a typical concert band cycle, and (c) the advantages and disadvantages that they perceived while applying democratic rehearsal procedures.

Respondents rated "identify and describe opportunities for individual and ensemble performance improvement" and "student-led sectionals" as important for their high school concert band students to experience. Other highly-rated procedures included "analyze, discuss, and make decisions regarding how the music should be performed" and "identify and select music segments for rehearsal." Perhaps band directors rated these items highly because they were easier to implement within existing rehearsal structures and allowed respondents to remain actively involved while developing a reciprocal relationship with their students (Collins et al., 2019). Although band directors indicated that providing students opportunities to actively participate in the rehearsal experience through error detection and correction and student-led sectionals was at least somewhat important, they also indicated that other procedures typically assigned to the director (i.e., music selection, score study, and full-ensemble rehearsal) were not considered as important. Additionally, respondents indicated that they did not believe students could successfully select and analyze music. Taken together, it seems possible that band directors were expressing a sense of insecurity about their own music preference and selection skills (Allsup, 2007). Similarly, it is possible that band directors may still be 
dealing with underlying concerns about the purpose and value of band-if their students were already capable of selecting and preparing music, then what is their purpose?

On a less philosophical level, respondents may have been hesitant to provide democratic experience because students have resisted unfamiliar power structures previously (Silverman, 2013). Or perhaps they were concerned over a wide variation in their students' abilities — controlled to some degree within sectionals, but more prominent in a full ensemble setting (Swanson, 2015). Additional research to examine how democratic rehearsals are implemented in school settings, how band directors adapt democratic principles to more traditional rehearsal models, and how self-identified democratic educators prepare students for democratic rehearsal experiences could prove beneficial for band directors and music teacher educators who may remain concerned about the practicality of adopting democratic procedures.

In-service band directors reported that they sometimes included several democratic rehearsal procedures within a typical concert cycle. Unsurprisingly, the most frequently included procedures were also those rated most important to experience (i.e., “identify and describe opportunities for individual and ensemble performance improvement" and "student-led sectionals"). Similarly, procedures rated of lower importance like "student-led full ensemble rehearsal" and "in-class collaborative score study" were also used less frequently. These results are consonant with McNamara's (2019) findings that teachers' definition of democracy influenced the kinds of activities they provided their students. It seems possible that an experience such as student-led sectionals was rated more highly because it is already a part of many band directors' rehearsal practices. Future researchers might investigate the value of student-led 
sectionals and the ways that band directors prepare students to participate and lead in concert band settings.

Responses to the open-ended question about barriers and limitations of applying democratic rehearsal procedures revealed several themes. Consonant with previous findings, the most frequently cited barrier for application was time (McNamara, 2019). Concerns related to student ability were also common and reflected Allsup's (2007) suggestion that "when teachers speak about democracy and education, there is always a bit of fear present in the conversation. One is likely to hear, 'If I took a vote, all we'd listen to is rap"' (p. 53). Although each of these barriers presents challenges for in-service band directors, careful planning and the use of scaffolded experiences within democratic structures may limit issues related to time and student ability level. Being able to access rehearsal spaces for sectionals and having necessary technological needs require inservice band directors to consider how and when to implement democratic rehearsal procedures. It may be that these concerns cause directors to feel that using these processes will result in not being adequately prepared for performances including competitions and festivals. However, collegiate musicians have successfully prepared for a performance at a state music conference using a conductor-less democratic model (Hedgecoth, 2018); therefore, it seems likely that democratic experiences facilitated by the director could produce similarly positive results. Researchers could examine whether high school musicians are capable of preparing music democratically and how this might influence perceptions of performance outcomes. Additionally, band directors might consider using democratic rehearsal procedures during a time in which their band is not preparing for adjudicated festivals so that teachers and students can gain experience using 
democratic rehearsal processes without the additional stress of competition and adjudication.

The most common advantages reported by in-service band directors were increased student ownership and engagement. Respondents also indicated that democratic rehearsal procedures aided in students' development as musicians and leaders. Collegiate musicians who participated in a democratic rehearsal cycle indicated that they felt like they grew musically during the experience (Hedgecoth, 2018) and previous research findings indicated that democratic practices increased students' positive attitudes toward school (Cleaver \& Riddle, 2014) and were viewed as fun and meaningful (Allsup, 2003). The results of the current study suggest that in-service high school band directors acknowledge that democratic rehearsal procedures may be beneficial for their students. Longitudinal studies of how band directors choose to implement democratic rehearsal procedures might encourage other directors to employ similar strategies that could help develop their students' musicianship and musical independence.

There are some limitations that should be noted. The generalizability of the results of this study is limited by the population surveyed. Therefore, care should be taken in generalizing these results to other ensembles (i.e., orchestra and choir) and age groups (i.e., beginning, intermediate, and advanced/professional ensembles). Additionally, all responses were matters of perception only, based on self-reported attitudes, frequency of application, and perceived disadvantages and advantages. Although I believe that educators answered questions truthfully, it is possible that they may have mischaracterized their applications as it can be difficult to generalize how frequently certain rehearsal procedures are used within an average rehearsal cycle. Future 
researchers may wish to examine the use of democratic procedures in an actual rehearsal environment.

\section{Implications for Teacher Educators}

Based on the findings of this study, I propose the following recommendations for music teacher educators. In-service band directors indicated generally positive attitudes toward democratic procedures, but did not consistently implement them in their rehearsals. Pre-service teachers are influenced by their collegiate (Bauer \& Berg, 2001) and student teaching experiences (Conway, 2002). Therefore, pre-service music teachers' rehearsal skills and technique preparation courses should include opportunities to facilitate and moderate democratic discussions that relate to musical elements or connect the music to larger societal discourse. Music teacher educators might also consider assigning the construction of an entire rehearsal cycle plan that includes democratic rehearsal procedures. Planning ahead may reduce the perceived time limitations associated with incorporating democratic experiences because pre-service educators will have set aside specific rehearsals for these activities. Additionally, ensemble directors could model student-led rehearsals and regular facilitation of student-led sectionals. It is important that pre-service teachers be provided opportunities during their formative collegiate experiences to engage in democratic rehearsals and have opportunities to practice democratic rehearsal skills because they may aid in preparing them to engage their future students in diverse music learning experiences.

Care must be taken to encourage the development of novice teachers' expertise without devaluing their abilities and past experiences. Respondents' belief that a primary limitation of applying democratic rehearsal procedures was students' lack of musical 
knowledge — although not without precedent (Allsup, 2007)—was concerning. The number of skills that pre-service educators must acquire during their undergraduate preparation is overwhelming. However, as music teacher educators prepare students, incorporating democratic practices (i.e., discussion and a reciprocal learning environment) that show respect for pre-service teachers' previous knowledge and experience may provide a model that aids our students in extending the same respect to their future students.

Additional research is needed to better understand how directors adopt, adapt, and implement democratic rehearsal practices. Preliminary results from this study indicated that respondents believed that democratic rehearsal procedures may prove useful in increasing students' positive attitudes, engagement, agency, leadership, and musical independence. Careful consideration of the formative experiences that we provide preservice teachers can aid in preparing future large ensemble educators who provide their students opportunities to engage with music in ways beyond just performing. Democratic rehearsal procedures may be one means of maintaining high performance expectations while developing ensemble members' musical independence. 


\section{Chapter Five}

\section{Summary and Conclusions}

Preparing students to participate in a democratic society requires careful consideration of the content and processes they experience during their formal education. Relying solely on lecture-based, teacher-centric approaches implies that students are empty vessels to be filled (Freire, 1968/2000). Adopting a democratic approach recognizes that students possess valuable knowledge and experiences that they can contribute to the learning process. In order for students to share their understanding and experiences, discussion is a primary means of engaging them democratically (Dewey, 1916). As the expert in the classroom, the teacher is responsible for providing scaffolded experiences that increase in sophistication as students mature (Dewey, 1916; Woodford, 2005). Additionally, they should ensure that discussion is nonrepressive and nondiscriminatory (Gutmann, 1987/1999) and that all perspectives-including nondominant viewpoints (Gould, 2007, 2008)_-are examined. In this environment, students gain content knowledge and valuable democratic skills like collaboration, critical thinking and problem-solving, and the ability to engage in civil discussion. Many of these same skills are part of contemporary educational objectives such as critical thinking and problem solving, communication, collaboration, and creativity and innovation, the four C's of $21^{\text {st }}$ century learning (NEA, n.d.). Because future independence is a goal of those who espouse democratic education, it seems likely that music educators could apply democratic principles to encourage students' musical independence (Weidner, 2020).

Findings from empirical investigations of democratic educational practices indicate that they may be a valuable tool for educators. Teachers believed that adopting 
democratic practices could positively impact their teaching efficiency (Schweisfurth, 2002), generate feelings of trust, empathy, and reflectiveness (Catalano \& Leonard, 2016), and aid in the development of student agency and independence (McNamara, 2019). Findings from investigations involving the large-scale implementation of democratic processes indicated that students' positive attitudes toward school increased (Cleaver \& Riddle, 2014), student well-being improved through collaborative studentteacher relationships (Simó et al., 2016), and future participation in traditional higher education environments was not affected negatively (Gray \& Chanoff, 1986). At the classroom level, democratic educational practices have increased students' feelings of openness (McAvoy \& Hess, 2013; Pennisi, 2013), empowerment and achievement (Simovska, 2011), problem solving and critical thinking skills (Brown, 2012), and agency, empathy, and reflection (Boatright \& Allman, 2018). Music education researchers have found that music students believed that democratic collaborations were valuable in small group composition (Allsup, 2003; Swanson, 2015) and music listening (Silverman, 2013) settings. Investigations within concert bands have focused on conductor-less ensembles (Hedgecoth, 2018; Weidner, 2019) with mixed results. No extant examinations involving concert band directors and their use of democratic rehearsal processes across an entire concert rehearsal cycle were found.

\section{Research Question and Method}

The purpose of this dissertation was to better understand experiences and perceptions of democratic education as applied in concert band settings. Specifically, I asked: What were collegiate concert band members lived experiences during a democratic rehearsal cycle? and What are high school band directors' beliefs and uses of 
democratic rehearsal procedures? In order to answer these questions, I completed a comprehensive review of literature (Chapter 2), a phenomenological inquiry of collegiate concert band members' lived experiences (Chapter 3), and a survey of high school concert band directors (Chapter 4). The following sections highlight the major findings from each of these investigations.

\section{Major Findings}

\section{Review of Literature}

The underlying principle of democratic education is that schools should prepare children to become independent members of a democratic society (Dewey, 1916). Understanding various content areas is an essential part of a good formal education, although the cultivation of students' agency, critical thinking skills, and their ability to participate collaboratively may be equally valuable for participation in a democratic society (Apple \& Beane, 1995). These functional skills have become increasingly desirable and are reflected in contemporary educational objectives (NCCAS, 2014; NEA, n.d.). Given the importance of preparing students for future independence and the close relationship between contemporary and democratic educational objectives, I identified and discussed non-music educators' proposals for cultivating these skills through process- and product-oriented means (Allen, 2011; Daly, 2002; Luff \& Webster, 2014; McDonell, 2014; Skovsmose, 1990). Process-oriented educators advocated for learning environments characterized by active student discussion and collaboration, whereas product-oriented educators emphasized situating and applying content knowledge within larger societal discourse. Regardless of the means by which democratic educational principles are applied, a reliance on simple consensus (Gould, 2007) and unfamiliar 
student-teacher power structures (Aguilar \& Zavaleta, 2012) were identified as potential issues that educators must consider carefully.

Democratic education has been examined within non-music (e.g., Cleaver \& Riddle, 2014; Collins et al, 2019; Ellis, 2013; Gray \& Chanoff, 1984; Helwig, 1998) and music (e.g., Allsup, 2003; Berglin, 2015; McNamara, 2019) content areas, but few researchers have investigated applications in concert band settings. Researchers have recently examined democratic ensembles that used a conductor-less model, resulting in mixed findings (Hedgecoth, 2018; Weidner, 2019). On the basis of these results, I concluded that investigators should explore democratic models that include the teacher acting as a facilitator. By including instrumental educators as facilitators, potential issues such as the repression of non-dominant viewpoints could potentially be mitigated. Furthermore, a model wherein the teacher remains an active member of the learning environment might be more approachable for educators accustomed to a teacher-centric process.

\section{Qualitative Study}

Using a phenomenological approach, I investigated collegiate musicians' lived experiences with democratic rehearsal procedures in a concert band setting. Participants $(N=42)$ were members of a non-auditioned university concert band at a large Midwestern university. I collected data for this study, which took place during an eightweek concert cycle, through pre- and post-questionnaires, weekly reflections, and three interviews with a subset of five participants who represented a cross-section of ensemble instrument families. Trustworthiness was established through data triangulation, peer 
review, bracketing to clarify researcher bias, and external coding review (Creswell, 2013).

Collegiate musicians expressed feelings of ownership and engagement and valued hearing multiple perspectives during the democratic rehearsal process. Active democratic participation included being performance focused, an engaged listener, and sharing ideas through verbal feedback in small and full ensemble settings. Regardless of their adopted role, participants enjoyed hearing from their peers and recognized that each brought a unique perspective based on past experiences and physical location within the ensemble. By considering, implementing, and discussing peer feedback during the rehearsal process, participants developed a sense of ensemble ownership. This feeling was most apparent after the final performance as participants reflected on a successful culminating experience that they helped actively shape.

The amount of time necessary for implementing effective democratic rehearsals and worries about becoming overbearing were challenges that concerned participants. At the beginning of the experience, some participants believed that adopting democratic practices could be problematic for an ensemble that only met once a week and was preparing several pieces for the concert, a concern that has been expressed by educators previously (Chapter 4; McNamara, 2019). Although nearly all participants indicated that the final performance was successful, some ensemble members cited the amount of time required for effective democratic rehearsal as a reason they would not look forward to similar experiences in the future. When providing feedback, participants were aware that becoming a primary voice could replace one leader (i.e., the band director) with another. Therefore, several participants who frequently provided verbal feedback indicated that 
they tried to limit their comments to two or three statements, allowing space for their colleagues to exercise their own agency.

Consonant with previous investigations, ensemble members' feedback and pedagogical strategies improved as they became more familiar with democratic rehearsal procedures (Weidner, 2019). However, some participants' hesitancy to provide feedback remained, especially when responding to ensemble members outside of their own instrument section. Participants already possessed the ability to analyze music and formulate ideas about how to improve performance, but early attempts were hindered due to limited experience providing and discussing ideas in an ensemble setting. Considering that all members of the ensemble had several years of experience playing their primary instrument $(M=8.90, S D=2.01$; with a range of 5 to 13 years $)$ and varying degrees of experience with democratic rehearsal procedures (most frequently sectionals), it seems more likely that, for some participants, previous lack of opportunities to apply their musical agency made them feel less knowledgeable than they actually were.

\section{Survey Study}

In order to better understand current high school band directors' perceptions and applications of democratic rehearsal procedures, I conducted a national survey of members of the National Association for Music Education (NAfME) who were high school band directors. Participants $(N=216)$ responded to items that comprised four survey sections: directors' (a) perceptions of democratic rehearsal procedures ( 7 items), (b) application of democratic rehearsal procedures (7 items), (c) experiences (both positive and negative) when applying democratic procedures (2 questions), and (d) demographic items. Respondents represented a wide range of teaching experience, self- 
identified communities (i.e., rural, urban, and suburban), and regions within the United States.

Respondents indicated that democratic rehearsal procedures which provided students opportunities to develop listening (i.e., identify and describe opportunities for individual and ensemble performance improvement, $M=4.28, S D=0.86$ ) and leadership skills (i.e., student-led sectionals, $M=4.12, S D=0.95$ ) were considered important for students to experience while in high school. However, other democratic rehearsal procedures (e.g., music selection, score study, and student-led full-ensemble rehearsal) were not considered as important. Unsurprisingly, respondents used democratic rehearsal procedures that they considered more important more frequently. However, only "identify and describe opportunities for individual and ensemble performance improvement" received a mean rating indicative of regular use $(M=3.80, S D=1.00)$.

Participants' responses to open-ended questions concerning their experiences (both positive and negative) related to implementing democratic rehearsal procedures revealed several themes. Issues related to (a) students' ability, (b) time limitations, (c) unfamiliar classroom dynamics, and (d) availability of classroom resources were identified as barriers to implementation. Respondents indicated that potential benefits of implementing democratic rehearsal procedures included (a) student ownership, (b) student engagement, (c) student growth as musicians and leaders, and (d) the value of multiple perspectives. Band directors' beliefs about potential benefits closely aligned with the findings of my phenomenological inquiry of collegiate musicians' experiences (Chapter 3). The lack of time for implementation was also a common finding between the two studies. 


\section{Discussion}

The investigations in this dissertation were conducted to better understand democratic educational processes within concert band settings. The in-service high school band directors who responded to the survey believed that democratic procedures such as (a) identify and describe opportunities for individual and ensemble performance improvement, (b) student-led sectionals, (c) analyze, discuss, and make decisions regarding how the music should be performed, and (d) identify and select music segments for rehearsal were important for their students to experience (Chapter 4). These same procedures were only sometimes included in a typical rehearsal cycle. Perhaps these procedures were not used more regularly due to respondents' concerns related to time, an issue similarly identified by K-12 music educators (Chapter 4; McNamara, 2019). Collegiate musicians also cited the amount of time democratic rehearsals would take when preparing for a concert as problematic (Chapter 3). Even after the final performance, some participants indicated that the amount of time was one reason they would not look forward to a similar democratic experience in the future. However, the rehearsal segments using democratic procedures were only slightly longer than those dedicated to other selections on the same concert (approximately 35 minutes for each democratic rehearsal versus 25-30 minutes of rehearsal time for each of the other pieces).

Consonant with the findings of a previous investigation (Hedgecoth, 2018), the final performance in my study was well-received and most participants considered it successful (Chapter 3). This seems to indicate that democratic experiences, whether scaffolded or conductor-less, may be used to successfully prepare for a concert; however, incorporating democratic practices embryonically might assist with time management 
concerns. Additionally, collegiate ensemble members' feedback and strategies improved over the course of a democratic rehearsal cycle (Chapter, 3; Weidner, 2019). Future examinations of time use in ensembles that have never applied democratic principles, those that occasionally incorporate them, and ensembles that frequently use them seems warranted. Perhaps time use is a barrier during initial implementation. However, it seems possible that time will become less of an issue as ensemble members gain experience rehearsing democratically.

High school band directors believed that democratic procedures would encourage student ownership, engagement, and leadership (Chapter 4). Consonant with the findings of previous investigations involving secondary students in non-music settings (Castro \& Grauer, 2010; Cleaver \& Riddle, 2014; Simovska, 2011), collegiate musicians described feelings of ownership and increased engagement during a democratic rehearsal cycle (Chapter 3). By incorporating democratic practices, band directors can encourage students to be active participants in their education and to develop a sense of ownership. It may also be a useful step toward students' development of musical independence (Weidner, 2020). Comparative investigations designed to assess student musicians' feelings of musical independence between democratic and traditional rehearsals could provide further evidence regarding the benefits of democratic procedures in large performing ensembles.

Results indicated that many band directors believed their students may not possess the ability to participate in democratic rehearsal procedures due to a lack of content knowledge or the ability to effectively apply it (Chapter 4). Similarly, some collegiate band members identified providing feedback outside of their primary section as 
a challenge within a democratic band rehearsal (Chapter 3). For these students, this challenge was more closely associated with feelings of comfort/connection to peers within their section and not a lack of ideas or understanding. Democratic educational practices have positively affected non-music students' critical thinking skills (Brown, 2012). In music contexts, these skills were related to the idea of musical voice (McNamara, 2019) and are part of contemporary educational learning objectives (NCCAS, 2014). Incrementally applying democratic rehearsal procedures may be one way to provide students the opportunity to develop the same critical thinking and rehearsal skills used by professional musicians.

\section{Suggestions for Educators}

High school band directors and collegiate musicians who participated in both of my studies expressed generally positive attitudes toward democratic rehearsal procedures. However, the band directors from my study indicated that they did not consistently include democratic rehearsal procedures during a typical rehearsal cycle (Chapter 4). The amount of time that rehearsing democratically required was a concern for both the band directors and collegiate musicians in my investigations. Although it seems likely that this challenge may primarily be related to how and when to implement these ideas, additional research is needed. Instrumental music educators might consider adopting an embryonic approach by scaffolding experiences until students demonstrate that they are capable of increased rehearsal responsibilities. Additionally, band directors might choose to reduce the frequency of democratic rehearsal experiences or forgo them altogether during a rehearsal cycle that culminates in a festival or contest rating. This would allow directors to use procedures they may feel more comfortable with since scores at large group 
festival are often correlated with teacher and program success (Rohrer, 2002). For directors who feel uncomfortable with democratic procedures, the final concert cycle of the year may be an opportunity to develop democratic skills for themselves and their students. Because this concert is typically held after adjudicated festivals and contests in the spring, incorporating democratic practices might help reduce student burnout by increasing engagement and provide an opportunity for the director to conduct summative assessments of students' learning during the academic year. Even if democratic procedures are only applied to one piece, they may prove invaluable for students' musical growth.

The use of democratic rehearsal procedures positively affected collegiate musicians' feelings of engagement and ownership, a finding that is consonant with previous research in non-music settings (Castro \& Grauer, 2010; Cleaver \& Riddle, 2014; Simovska, 2011). Pedagogical approaches that increase student agency, ownership, and engagement—such as democratic rehearsal procedures—can be valuable tools for instrumental educators to positively influence student achievement, musical independence, and well-being. For example, band directors might consider implementing a regular student-led rehearsal where ensemble members provide feedback about musical elements such as dynamics, phrasing, and balance. The execution of this rehearsal could vary based on the ability of the students with the band director taking more responsibility by providing pedagogical solutions for less experienced students. Another way to encourage student musicianship could be adopting a rehearsal procedure where, instead of providing feedback after stopping the ensemble, the director has students share ideas for individual, sectional, or ensemble improvement with stand partners or nearby 
ensemble members. This could be followed by a discussion with the entire ensemble and multiple attempts to use that feedback to improve ensemble performance.

Results indicated that a lack of student ability was one potential limitation identified by band directors related to implementing democratic rehearsal procedures. Developing students' ability to participate in decisions about music selection and preparation are part of contemporary educational learning objectives for performing ensembles (NCCAS, 2014). College student participants who were hesitant to provide feedback to peers outside of their own section were likely responding to unfamiliarity with members of the ensemble (Chapter 3) — an issue that may be less pertinent for secondary school music students who typically move together as a cohort. Additionally, it seems likely that college ensemble member participants' hesitance to provide feedback was also related to unfamiliar rehearsal procedures because students were not regularly included as active participants in previous rehearsal experiences (Gieblehausen \& Kruse, 2017; Silverman, 2013). Instrumental teachers could incorporate democratic procedures more frequently as a way to encourage students' musical development and as a means of informal assessment.

Music teacher educators might also consider ways to prepare future educators to teach democratically. Incorporating democratic rehearsal procedures within conducting and rehearsal techniques coursework could provide pre-service teachers with the opportunity to practice facilitating and moderating discussion in their classes. Pre-service teachers might also be given an assignment to construct a concert cycle plan that includes democratic rehearsal procedures. By thinking about rehearsal objectives over the entire rehearsal cycle, pre-service teachers might become more comfortable organizing 
rehearsals that allow their students to use their agency within the context of a longer rehearsal cycle. Finally, music teacher educators might consider ways to incorporate democratic practices that respect students' abilities and past musical and rehearsal experiences. Modeling a reciprocal student-teacher relationship may aid pre-service teachers in developing similar teaching practices.

\section{Conclusion}

I designed this dissertation to examine perceptions and experiences of democratic educational practices in concert band settings. Based on my findings, democratic rehearsal procedures appear to be valuable tools for high school concert band directors. Collegiate musicians were able to prepare and present a successful performance using democratic rehearsal procedures. Participants found the experience valuable, and themes of ownership, musical agency, and engagement indicated the positive influence that adopting democratic procedures had on a group of collegiate musicians. High school concert band directors identified ownership, engagement, and leadership as potential benefits of democratic procedures and believed they were important for students to experience; however, respondents were not consistent in their applications of these procedures. Future research designed to examine democratic practices applied within other large performing ensembles (i.e., choirs and orchestras) and with musicians of other ages is needed. Additionally, longitudinal studies concerning how much time democratic practices require compared to traditional teacher-centric approaches should also be conducted. Democratic rehearsals may be beneficial for educators and students in that they encourage students to develop their musical voice and independence. They also provide educators opportunities to assess musical understanding and aid in the 
development of an open learning environment. By adopting and using democratic educational practices in their music classrooms, educators can provide excellent and thought-provoking musical instruction while also developing students' abilities to collaborate, exercise agency and independence, and think critically. 


\section{References}

Aguilar, M. S. \& Zavaleta, J. G. M. (2012). On the links between mathematics education and democracy: A literature review. Pythagoras, 33(2), 1-15. https://doi.org/10.4102/pythagoras.v33i2.164

Allen, K. (2011). Mathematics as thinking: A response to "democracy and school math." Democracy \& Education, 19(2), 1-7. https://democracyeducationjournal.org/home/vol19/iss2/10/

Allsup, R. E. (2003). Mutual learning and democratic action in instrumental music education. Journal of Research in Music Education, 51(1), 24-37. https://doi.org/10.2307/3345646

Allsup, R. E. (2007). Democracy and one hundred years of music education. Music Educators Journal, 93(5), 52-56. https://doi.org/10.1177/002743210709300517

Allsup, R. E. (2016). Remixing the classroom: Toward an open philosophy of music education. Indiana University Press.

Allsup, R. E., \& Benedict, C. (2008). The problems of band: An inquiry into the future of instrumental music education. Philosophy of Music Education Review, 16(2), 156-173. https://www.jstor.org/stable/40327299

Apple, M. W., \& Beane, J. A. (Eds.). (1995). Democratic schools. Association for Supervision and Curriculum Development.

Bauer, W. I., \& Berg, M. H. (2001). Influence on instrumental music teaching. Bulletin of the Council for Research in Music Education, (150), 53-66.

https://www.jstor.org/stable/40319099 
Berglin, J. (2015). "It's much more collaborative": Democratic action in contemporary collegiate a cappella. Bulletin of the Council for Research in Music Education, (205), 51-69. https://www.jstor.org/stable/10.5406/bulcouresmusedu.205.0051

Boatright, M. D., \& Allman, A. (2018). Last year's choice is this year's voice: Valuing democratic practices in the classroom through student-selected literature.

Democracy \& Education, 26(2), 1-8.

https://democracyeducationjournal.org/home/vol26/iss $2 / 2$

Brelias, A. (2015). Mathematics for what? High school students reflect on mathematics as a tool for social inquiry. Democracy \& Education, 23(1), 1-11. https://democracyeducationjournal.org/home/vol23/iss 1/4

Brown, S. (2012). Transaction circles with digital texts as a foundation for democratic practices. Democracy \& Education, 23(2), 1-12.

https://democracyeducationjournal.org/home/vol23/iss $2 / 4$

Butler-Kisber, L. (2010). Qualitative inquiry: Thematic, narrative and arts-informed perspectives. Sage Publications.

Castro, J. C., \& Grauer, K. (2010). Structuring democratic places of learning: The gulf island film and television school. Art Education, 63(5), 14-21. https://www.jstor.org/stable/20799832

Catalano T., \& Leonard, A. E. (2016). Moving people and minds: Dance as a vehicle of democratic education. Education, Citizenship and Social Justice, 11(1), 63-84. https://doi.org/10.1177/1746197915626082

Cleaver, D. \& Riddle, S. (2014). Music as engaging, educational matrix: Exploring the case of marginalized student attending an "alternative" music industry school. 
Research Studies in Music Education, 36(2), 245-256.

https://doi.org/10.1177/1321103X14556572

Collins, J., Hess, M. E., \& Lowery, C. L. (2019). Democratic spaces: How teachers establish and sustain democracy and education in their classrooms. Democracy \& Education, 27(1), 1-12. https://democracyeducationjournal.org/home/vol27/iss1/3

Conway, C. M. (2002). Perceptions of beginning teachers, their mentors, and administrators regarding preservice music teacher preparation. Journal of Research in Music Education, 50(1), 20-36. https://doi.org/10.2307/3345690

Creswell, J. W. (2013). Qualitative inquiry \& research design: Choosing among five approaches. Sage Publications.

Daly, A. (2002). Dancing democracy. Dance Research Journal, 34(2), 8-11. https://www.jstor.org/stable/1478455

DeLorenzo, L. C. (2003). Teaching music as democratic practice. Music Educators Journal, 90(2), 35-40. https://doi.org/10.2307/3399932

Denzin, N. K., \& Lincoln, Y. S. (Eds.). (2005). The Sage handbook of qualitative research (3rd ed.). Sage Publications.

Dewey, J. (1916). Democracy and education: An introduction to the philosophy of education. The Macmillan Company.

Draper, A. R. (2019). Democracy in the middle school music classroom. Music Educators Journal, 105(3), 17-22. https://doi.org/10.1177/0027432118816147

Egger, J. O., \& Springer, D. G. (2018). Music educators' understanding and opinions of U.S. copyright law. Update: Application of Research in Music Education, 37(3), 20-27. https://doi.org/10.1177/8755123318801064 
Ellis, L. (2013). Why does he want a dictator? Action research on democratic classroom decision making. English Education, 45(4), 385-401. https://www.jstor.org/stable/24570981

Elpus, K. \& Abril, C. R. (2019). Who enrolls in high school music? A national profile of U.S. students. Journal of Research in Music Education, 67(3), 323-338. https://doi.org/10.1177/0022429419862837

Freire, P. (2014). Pedagogy of the oppressed (M. Bergman Ramos, Trans.) Bloomsbury Academic. (Original work published 1968).

Giebelhausen, R. \& Kruse, A. J. (2017). “A smile on everybody’s face” A multiple case study of community ukulele groups. International Journal of Music Education, 36(3), 347-365. https://doi.org/10.1177/0255761417744371

Gould, E. (2007). Social justice in music education: The problematic of democracy. Music Education Research, 9(2), 229-240. https://doi.org/10.1080/14613800701384359

Gould, E. (2008). Devouring the other: Democracy in music education. Action, Criticism, and Theory for Music Education, 7(1), 29-44. http://act.maydaygroup.org/articles/Gould7_1.pdf

Gray, P., \& Chanoff, D. (1984). When play is learning: A school for self-directed education. Phi Delta Kappa International, 65(9), 608-611. https://www.jstor.org/stable/20387146

Gray, P. \& Chanoff, D. (1986). Democratic schooling: What happens to young people who have charge of their own education? American Journal of Education, 94(2), 182-213. https://www.jstor.org/stable/1084948 
Green, L. (2008). Music, informal learning and the school: A new classroom pedagogy. Ashgate.

Gutmann, A. (1999). Democratic education. Princeton University Press. (Original work published 1987)

Hauver, J. (2017). "State you defense!" Children negotiate analytic frames in the context of deliberative dialogue. Democracy \& Education, 25(2), 1-13. https://democracyeducationjournal.org/home/vol25/iss2/3

Hedgecoth, D. M. (2018). Student perspectives and learning outcomes from self-guided ensemble rehearsal. Research \& Issues in Music Education, 14(1) 1-27. https://commons.lib.jmu.edu/rime/vol14/iss1/5/

Helwig, C. C. (1998). Children's conceptions of fair government and freedom of speech. Child Development, 69(2), 518-531. https://doi.org/10.1111/j.14678624.1998.tb06205.x

Hemmings, A. (2000). High school democratic dialogue: Possibilities for praxis. American Educational Research Journal, 37(1), 67-91. https://www.jstor.org/stable/1163472

Jagers, R. J., Lozada, F. T., Rivas-Drake, D., \& Guillaume, C. (2017). Classroom and school predictors of civic engagement among black and Latino middle school youth. Child Development, 88(4), 1125-1138. https://doi.org/10.1111/cdev.12871

Kratus, J. (2007). Music education at the tipping point. Music Educators Journal, 94(2), 42-48. https://doi.org/10.1177/002743210709400209

Lincoln, Y., \& Guba, E. (1985). Naturalistic inquiry. Sage Publications. 
Luff, P. \& Webster, R. (2014). Democratic and participatory approaches: Exemplars from early childhood education. Management in Education, 28(4), 138-143. https://doi.org/10.1177/0892020614547317

Marcetti, T. (2019). Experiential ensembles: A leap of faith. Teaching Music, 27(1), 2430.

McAvoy, P., \& Hess, D. (2013). Classroom Deliberation in an era of political polarization. Curriculum Inquiry, 43(1), 14-47. https://doi.org/10.1111/curi.12000

McDonnell, J. (2014). Reimagining the role of art in the relationship between democracy and education. Educational Philosophy and Theory, 46(1), 46-58, https://doi.org/10.1111/j.1469-5812.2011.00802.x

McNamara, S. C. (2019) An examination of democracy in music education [Doctoral dissertation, Indiana University]. ProQuest Dissertations and Theses Global.

Mertens, D. M. (2010). Research and evaluation in education and psychology: Integrating diversity with quantitative, qualitative, and mixed methods $\left(3^{\mathrm{rd}} \mathrm{ed}.\right)$. Sage Publications.

Moustakas, C. (1994). Phenomenological research methods. Sage Publications.

National Coalition for Core Arts Standards. (2014). National Core Arts Standards: A frame-work for arts learning. https://www.nationalartsstandards.org/

National Education Association. (n.d.). An educators guide to the "Four Cs": Preparing 21st century students for a global society. https://www.nea.org/tools/52217.htm

Patton, M. Q. (2015). Qualitative research \& evaluation methods (4th ed.). Sage Publications. 
Pennisi, A. C. (2013). Negotiating to engagement: Creating an art curriculum with eighth-graders. Studies in Art Education, 54(2), 127-140. https://doi.org/10.1080/00393541.2013.11518888

Rohrer, T. P. (2002). The debate on competition in music in the twentieth century. Update: Applications of Research in Music Education, 21(1), 38-47. https://doi.org/10.1177/87551233020210010501

Ross, D. D., \& Yeager, E. (1999). What does democracy mean to prospective elementary teachers. Journal of Teacher Education, 50(4), 255-266. https://doi.org/10.1177/002248719905000403

Saldaña, J. (2016). The coding manual for qualitative researchers (3rd ed.). Sage Publications.

Saldaña, J. \& Omasta, M. (2018). Qualitative research: Analyzing life. Sage Publications. Sant, E. (2019). Democratic education: A theoretical review (2006-2017). Review of Educational Research, 89(5), 655-696. https://doi.org/10.3102/0034654319862493

Schmidt, P. (2005). Music education as transformative practice: Creating new frameworks for learning music through a Freirian perspective. Visions of Research in Music Education, 6, 1-14. http://wwwusr.rider.edu/ vrme/v6n1/visions/Schmidt\%20Music\%20Education\%20as\%20Tr ansformative\%20Practice.pdf

Schmuck, P. \& Schmuck, R. (1990). Democratic participation in small-town schools. Educational Researcher, 19(8), 14-19. https://doi.org/10.3102/0013189X019008014 
Schwesifurth, M. (2002). Democracy and teacher education: Negotiating practice in the Gambia. Comparative Education, 38(3), 303-314.

http://www.jstor.org/stable/3099519

Silverman, M. (2013). A critical ethnography of democratic music listening. British Journal of Music Education, 3(1), 7-25.

https://doi.org/10.1017/S0265051712000423

Silvey, B. A., Springer, D. G., \& Eubanks, S. C. (2016). An examination of university conducting faculty members' score study attitudes and practices. Journal of Music Teacher Education, 26(1), 82-95. https://doi.org/10.1177/1057083715616442

Simó, N., Parareda, A., \& Domingo, L. (2016). Towards a democratic school: The experience of secondary school pupils. Improving Schools, 19(3), 181-196. https://doi.org/10.1177/1365480216631080

Simovska, V. (2011). Case study of a participatory health-promotion intervention in school. Democracy \& Education, 20(1), 1-10. https://democracyeducationjournal.org/home/vol20/iss1/4/

Sims, W. L., \& Cassidy, J. W. (2016). The role of the dissertation in music education doctoral programs. Journal of Music Teacher Education, 25(3), 65-77. https://doi.org/10.1177/1057083715578285

Skovsmose, O. (1990). Mathematical Education and Democracy. Educational Studies in Mathematics, 21(2), 109-128. https://www.jstor.org/stable/3482477

Swanson, M. S. (2015). Composing democracy: Collective identity formation in small group composition (Publication No. 10000157) [Doctoral dissertation, University of Washington]. ProQuest Dissertation \& Thesis Global. 
Tan, L. (2014). Towards a transcultural theory of democracy for instrumental music education. Philosophy of Music Education Review, 22(1), 61-77. https://www.jstor.org/stable/10.2979/philmusieducrevi.22.1.61

Weidner, B. N. (2019, September 12-14). Democracy in action: Student experiences and perceptions of the conductor-less concert band [Poster presentation]. Symposium for Music Teacher Education, Greensboro, NC.

Weidner, B. N. (2020). A grounded theory of musical independence in the concert band. Journal of Research in Music Education. Advanced online publication. https://doi.org/10.1177/0022429419897616

Williams, D. A. (2011). The elephant in the room. Music Educators Journal, 98(1), 5157. https://www.jstor.org/stable/23012641

Woodford, P. G. (2005). Democracy and music education: Liberalism, ethics, and the politics of practice. Indiana University Press. 


\section{Appendix A}

October 03, 2019

Principal Investigator: Alec David Scherer Department: School of Music

Your IRB Application to project entitled High School Band Directors' Perceptions and Applications of Democratic Procedures in Concert Band Rehearsals was reviewed and approved by the MU Institutional Review Board according to the terms and conditions described below:

$\begin{array}{ll}\text { IRB Project Number } & 2017613 \\ \text { IRB Review Number } & 254465 \\ \text { Initial Application Approval Date } & \text { October 03, 2019 } \\ \text { IRB Expiration Date } & \text { October 03, 2020 } \\ \text { Level of Review } & \text { Exempt } \\ \text { Project Status } & \text { Active - Exempt } \\ \text { Exempt Categories (Revised Common } & 45 \text { CFR 46.104d(2) } \\ \text { Rule) } & \\ \text { Risk Level } & \text { Minimal Risk }\end{array}$

The principal investigator (PI) is responsible for all aspects and conduct of this study. The PI must comply with the following conditions of the approval:

1. No subjects may be involved in any study procedure prior to the IRB approval date or after the expiration date.

2. All changes must be IRB approved prior to implementation utilizing the Exempt Amendment Form.

3. The Annual Exempt Form must be submitted to the IRB for review and approval at least 30 days prior to the project expiration date to keep the study active or to close it.

4. Maintain all research records for a period of seven years from the project completion date.

If you are offering subject payments and would like more information about research participant payments, please click here to view the MU Business Policy and Procedure: http://bppm.missouri.edu/chapter2/2_250.html

If you have any questions or concerns, please contact the MU IRB Office at 573-882-3181 or email to muresearchirb@missouri.edu.

Thank you,

MU Institutional Review Board 


\title{
Appendix B
}

\section{CONSENT FORM TO PARTICIPATE IN A RESEARCH STUDY}

\author{
Collegiate Musicians' Experiences with Democratic Rehearsal Processes \\ Conducted by: Alec D. Scherer \\ School of Music, The University of Missouri \\ Telephone: 573.882 .3439 \\ Email: ads8cg@mail.missouri.edu
}

You are being asked to participate in a research study. This form provides you with information about the study. Please read the information below and ask questions about anything you do not understand before deciding whether or not to take part. Your participation is voluntary and you can refuse to participate without penalty or loss of benefits to which you are otherwise entitled. All identifying information will be kept confidential.

The purpose of this study is to examine collegiate musicians' experience with democratic rehearsal processes.

If you agree to participate in this study, I will ask you to do the following things:

- Describe your experiences during the rehearsal process in a pre- and post-rehearsal cycle questionnaire.

- Describe your rehearsal experiences during weekly rehearsals and post-rehearsal reflections.

If you agree to participate in interviews, I will ask you to do the following things:

- Complete three 45-min interviews over the course of the rehearsal cycle.

- Elaborate on your rehearsal experiences.

The total estimated time to participate in the study varies based on level of participation.

Risks and Benefits:

The risk associated with this study is no greater than everyday life. The possible benefits of this study include reflecting on democratic rehearsal experiences.

\section{Confidentiality:}

The evaluation forms used in this study will be stored securely and kept confidential.

\section{Contacts and Questions:}

If you have any questions about the study, please contact me, my contact information is at the top of the page.

You may contact the University of Missouri - Columbia Institutional Review Board (IRB) if you have questions about your rights as a research participant. The IRB can be reached by phone at 573-8823181 or emailirb@missouri.edu.

By completing the following questionnaire you indicate your consent to participate in this research study. 


\section{Appendix C}

\section{Pre-Questionnaire}

Q1. Please circle any of the following democratic rehearsal procedures you have experienced.

- Helped to select music for performance

- Participated in score study/preparation

- Identified and selected music segments for rehearsal

- Identified and described opportunities for performance improvement

- Provided feedback to peers

- Presented, discussed, and made decisions regarding how the music should be performed

- Participated in student-led sectionals

- Participated in student-led full ensemble rehearsal

- Other (please describe in the space below)

Q2. How does the idea of participating in a rehearsal cycle using democratic rehearsal procedures make you feel?

Q3. What previous experiences affect how you feel about participating in a rehearsal cycle using democratic rehearsal procedures? 
Q4. What gender do you identify with?

- Male

- Female

- Non-binary/Third gender

- Prefer not to respond

Q5. How old are you?

Q6. What is your primary instrument?

Q7. Including the current year, how many years have you played your primary instrument?

Q8. What was the average size of your high school band program?

Q9. What was the average size of your high school concert band?

Q11. Are you willing to be individually interviewed three times over the course of the rehearsal cycle?

- Yes

- No 


\section{Appendix D}

\section{Weekly Reflection}

Q1. How effective was rehearsal today? Please explain.

Q2. What are the most important musical elements/rehearsal segments for the ensemble to examine during the next rehearsal? Why?

Q3. Do you feel like you contributed to rehearsal today? Please explain.

Q4. How did today's rehearsal make you feel? Please explain. 


\section{Appendix E}

\section{Interview Questions}

Interview 1 Questions

- What is your music background?

○ Teachers

Favorite Groups to Play in/Hear

- Memorable musical experiences

- What does a democratic rehearsal process mean to you?

- When you heard about undertaking a democratic rehearsal process what was your initial reaction? Why?

- Describe your rehearsal experience over the first few rehearsals.

- How is this experience different than a "normal" rehearsal?

- How has your UBand experienced changed during this process?

- In what ways has your contribution to the ensemble changed?

- How does the rehearsal experience make you feel?

\section{Interview 2 Questions}

- Describe your rehearsal experience over the last few rehearsals.

- How is this experience different than a "normal" rehearsal?

- Has your UBand experience changed during this process?

- In what ways has your contribution to the ensemble changed?

- How does the rehearsal experience make you feel? 
Interview 3 Questions

- Describe your rehearsal experience over the last few rehearsals.

- How is this experience different than a "normal" rehearsal?

- How has your UBand experience changed during this process?

- In what ways has your contribution to the ensemble changed?

- How does the rehearsal experience make you feel?

- After the performance, how did you feel? Was this different than other performances? How?

- Would you look forward to participating in a similar rehearsal experience? Why or why not? 


\section{Appendix F}

\section{Post-Questionnaire}

Please reflect on the entire Polly Oliver rehearsal process and answer the following questions.

Q1. How did participating in a democratic rehearsal process make you feel?

Q2. What challenges, if any, resulted from participating in this process?

Q3. What advantages, if any, resulted from participating in this process? 
Q4. Should large instrumental ensemble rehearsals be more democratic? Why or why not?

Q5. Please provide any other comments you may have about the rehearsal process. 
Q6. In what ways did the democratic process affect the final performance?

Q7. From an ensemble perspective, how successful was the final performance?

Thank you for your participation in this research study. 


\section{Appendix G}

\section{Invitation Email}

\section{Email Subject Line: Survey of Democratic Rehearsal Procedures}

Greetings! I hope that you will consider completing a brief 10-minute survey about your perceptions and applications of democratic rehearsal procedures within concert band rehearsals. This research will provide insight into current practices and experiences related to the National Core Arts Standards.

The purpose of this study is to examine high school band directors' perceptions and applications of democratic procedures in concert band rehearsals. You will respond to questions regarding your (a) perceptions of the importance of democratic rehearsal procedures, (b) applications of democratic rehearsal procedures, and (c) perceptions of advantages and disadvantages when applying these procedures.

Your responses to the survey questions will be completely confidential.

If you have any questions about your rights as a research participant, you may contact me, Alec Scherer at (xxx).xxx.xxxx or the University of Missouri Institutional Review Board (IRB) at 573.882.3181. Feel free to contact me if you have any questions about this research.

https://missouri.qualtrics.com/jfe/form/SV_3vEzwRTRSJjA7hH

Alec D. Scherer, University of Missouri Doctoral Candidate, 202B Loeb Hall, Columbia, MO 65211;

(xxx).xxx.xxxx; ads8cg@mail.missouri.edu.

This invitation is sent as a service to the profession by NAfME, as part of our ongoing efforts to support research in music education. The sending of this invitation does not constitute endorsement of the content or quality of the research project for which this invitation is sent by NAfME or its component Societies or Councils. 


\section{Appendix H}

October 03, 2019

Principal Investigator: Alec David Scherer

Department: School of Music

Your IRB Application to project entitled Collegiate Musicians' Experiences with Democratic Rehearsal Procedures was reviewed and approved by the MU Institutional Review Board according to the terms and conditions described below:

$\begin{array}{ll}\text { IRB Project Number } & 2017611 \\ \text { IRB Review Number } & 254452 \\ \text { Initial Application Approval Date } & \text { October 03, 2019 } \\ \text { IRB Expiration Date } & \text { October 03, 2020 } \\ \text { Level of Review } & \text { Exempt } \\ \text { Project Status } & \text { Active - Exempt } \\ \text { Exempt Categories (Revised Common } & \text { 45 CFR 46.104d(2) } \\ \text { Rule) } & \text { Minimal Risk } \\ \text { Risk Level } & \end{array}$

The principal investigator (PI) is responsible for all aspects and conduct of this study. The PI must comply with the following conditions of the approval:

1. No subjects may be involved in any study procedure prior to the IRB approval date or after the expiration date.

2. All changes must be IRB approved prior to implementation utilizing the Exempt Amendment Form.

3. The Annual Exempt Form must be submitted to the IRB for review and approval at least 30 days prior to the project expiration date to keep the study active or to close it.

4. Maintain all research records for a period of seven years from the project completion date.

If you are offering subject payments and would like more information about research participant payments, please click here to view the MU Business Policy and Procedure: http://bppm.missouri.edu/chapter2/2_250.html

If you have any questions or concerns, please contact the MU IRB Office at 573-882-3181 or email to muresearchirb@missouri.edu.

Thank you,

MU Institutional Review Board 


\section{Appendix I}

\section{High School Band Directors' Perceptions and Applications of Democratic Rehearsal Procedures in Band}

Start of Block: Default Question Block

High School Band Directors' Perceptions and Applications of Democratic Rehearsal Procedures in Concert Band Rehearsals

Conducted by: Alec D. Scherer

School of Music, The University of Missouri

Telephone: 573.882.3439

Email: ads8cg@mail.missouri.edu

You are being asked to participate in a research study. This form provides you with information about the study. Please read the information below and ask questions about anything you do not understand before deciding whether or not to take part. Your participation is entirely voluntary and you can refuse to participate without penalty or loss of benefits to which you are otherwise entitled. You can stop your participation at any time and your refusal will not impact current or future relationships with MU or participating sites.

The purpose of this study is to examine high school band directors' perceptions and applications of democratic rehearsal procedures in concert band rehearsals.

If you agree to participate in this study, we will ask you to do the following things: Rate the importance of democratic rehearsal procedures in concert band rehearsals. Report the frequency with which these procedures are applied in your concert band rehearsals.

Consider the barriers/limitations of democratic rehearsal procedures in concert band rehearsals.

Consider the strengths and/or weaknesses of democratic rehearsal procedures in concert band rehearsals.

The total estimated time to participate in the study is 10 minutes.

\section{Risks and Benefits:}

The risk associated with this study is no greater than everyday life. The possible benefits of this study include reflecting upon democratic rehearsal practices.

\section{Confidentiality:}

The evaluation forms used in this study will be stored securely and kept anonymously. 


\section{Contacts and Questions:}

If you have any questions about the study, please contact me, my contact information is at the top of this page.

You may contact the University of Missouri - Columbia Institutional Review Board (IRB) if you have questions about your rights as a research participant. The IRB can be reached by phone at 573-882-3181 or email irb@ missouri.edu.

To consent to this research and begin the study, press the "Next" button below.

\section{End of Block: Default Question Block}

\section{Start of Block: Block 1}

Do you currently teach high school (grades 9-12) concert band?

$$
\begin{aligned}
& \text { Yes (1) } \\
& \text { No (2) }
\end{aligned}
$$

Skip To: Q2 If Do you currently teach high school (grades 9-12) concert band? = Yes

Skip To: End of Survey If Do you currently teach high school (grades 9-12) concert band? = No 
INSTRUCTIONS: Please provide your honest response to the questions below regarding your perceptions of democratic rehearsal procedures.

1. Please rate how important you believe it is that band students experience each of the following democratic rehearsal procedures during an academic year while in high school concert band.

$\begin{array}{ccccc}\text { Not at All } & \text { Of Little } & \text { Of Average } & \text { Important } & \text { Very } \\ \text { Important } & \text { Importance } & \text { Importance } & 4 & \text { Important } \\ 1 & 2 & 3 & & 5\end{array}$

Select music for performance

Participate in inclass collaborative score study/preparation

Identify and select music segments for rehearsal

Identify and describe opportunities for individual and ensemble performance improvement

Analyze, discuss, and make decisions regarding how the music should be performed

Student-led sectionals

Student-led full ensemble rehearsal 
2. Please rate how frequently your students experience each of the following democratic rehearsal procedures during a typical concert band rehearsal cycle.

\begin{tabular}{|c|c|c|c|c|c|}
\hline & $\begin{array}{c}\text { Never } \\
1\end{array}$ & $\begin{array}{c}\text { Rarely } \\
\quad 2\end{array}$ & $\begin{array}{c}\text { Sometimes } \\
3\end{array}$ & $\begin{array}{c}\text { Often } \\
4\end{array}$ & $\begin{array}{c}\text { Almost } \\
\text { Always } \\
5\end{array}$ \\
\hline $\begin{array}{l}\text { Select music for } \\
\text { performance }\end{array}$ & & & & & \\
\hline $\begin{array}{l}\text { Participate in in- } \\
\text { class } \\
\text { collaborative } \\
\text { score } \\
\text { study/preparation }\end{array}$ & & & & & \\
\hline $\begin{array}{l}\text { Identify and } \\
\text { select music } \\
\text { segments for } \\
\text { rehearsal }\end{array}$ & & & & & \\
\hline $\begin{array}{l}\text { Identify and } \\
\text { describe } \\
\text { opportunities for } \\
\text { individual and } \\
\text { ensemble } \\
\text { performance } \\
\text { improvement }\end{array}$ & & & & & \\
\hline $\begin{array}{l}\text { Analyze, discuss, } \\
\text { and make } \\
\text { decisions } \\
\text { regarding how } \\
\text { the music should } \\
\text { be performed }\end{array}$ & & & & & \\
\hline $\begin{array}{l}\text { Student-led } \\
\text { sectionals }\end{array}$ & & & & & \\
\hline $\begin{array}{l}\text { Student-led full } \\
\text { ensemble } \\
\text { rehearsals }\end{array}$ & & & & & \\
\hline
\end{tabular}


3. Are there other democratic procedures that were not mentioned in the previous prompts that you use? If so, please list those procedures.

\section{End of Block: Block 2}

\section{Start of Block: Block 3}

4. Describe any barriers/limitations that you have encountered when applying democratic rehearsal procedures within concert band rehearsals.

5. Describe the strengths/advantages that you have encountered when applying democratic rehearsal procedures within concert band rehearsals. 
6. From what resources, if any, have you learned about democratic rehearsal procedures?

\section{End of Block: Block 3}

\section{Start of Block: Demographics}

What gender do you identify with?

Male (1)

Female (2)

Non-binary/Third gender (3)

Prefer not to respond (4)

How old are you?

\section{Page Break}


Have you completed a bachelor's degree?

Yes

No

Other (please specify)

\section{Skip To: If Have you completed a bachelor's degree? $=$ No}

\section{Display This Question:}

If Have you completed a bachelor's degree? = Yes

In which area did you receive your bachelor's degree?

Music education

Conducting

Music performance

Music therapy

Jazz studies

Music theory or composition

Musicology or ethnomusicology

Other (please specify) 
Have you completed any graduate degrees?

Masters degree in progress

Masters degree completed

Doctoral degree in progress

Doctoral degree completed

No additional graduate degrees

\section{Skip To: If Have you completed any graduate degrees? = Masters degree in progress}

Display This Question:

If Have you completed any graduate degrees? = Masters degree in progress

What graduate degree are you currently completing?

Music education (1)

Conducting (2)

Music performance (3)

Music therapy (4)

Jazz studies (5)

Music theory or composition (6)

Musicology or ethnomusicology (7)

Other (please specify) (8) 
In which area did you receive your Masters degree?

Music education

Conducting

Music performance

Music therapy

Jazz studies

Music theory or composition

Musicology or ethnomusicology

Other (please specify)

Display This Question:

If Have you completed any graduate degrees? = Doctoral degree in progress 
In which area did you receive your Masters degree?

Music education

Conducting

Music performance

Music therapy

Jazz studies

Music theory or composition

Musicology or ethnomusicology

Other (please specify)

Display This Question:

If Have you completed any graduate degrees? = Doctoral degree in progress 
What graduate degree are you currently completing?

Music education

Conducting

Music performance

Music therapy

Jazz studies

Music theory or composition

Musicology or ethnomusicology

Other (please specify)

Display This Question:

If Have you completed any graduate degrees? = Doctoral degree completed 
In which area did you receive your Masters degree?

Music education

Conducting

Music performance

Music therapy

Jazz studies

Music theory or composition

Musicology or ethnomusicology

Other (please specify)

Display This Question:

If Have you completed any graduate degrees? = Doctoral degree completed 
In which area did you receive your Doctoral degree?

Music education

\section{Conducting}

Music performance

Music therapy

Jazz studies

Music theory or composition

Musicology or ethnomusicology

Other (please specify) 
Do you teach part-time or full-time?

\section{Part-time}

Full-time

Including the current year, how many years have you been teaching high school concert band?

Including the current year, how many years have you been teaching high school concert band at your current school?

What population area does your school serve?

\section{Rural}

Suburban

Urban

How many students currently participate in the high school band program at your school?

What is the average concert band ensemble size at your high school? 
In which NAfME region do you teach?

Eastern (CT, DC, DE, ME, MD, MA, NH, NJ, NY, PA, RI, VT)

North Central (IL, IN, IA, MI, MN, NE, ND, OH, SD, WI)

Northwest (AK, ID, MT, OR, WA, WY)

Southern (AL, FL, GA, KY, LA, MS, NC, SC, TN, VA, WV)

Southwestern (AR, CO, KS, MO, NM, OK, TX)

Western (AZ, CA, HI, NV, UT)

Based on some previous responses, additional information from study participants may be beneficial. If you consent to being contacted again, follow-up questions will be sent to you via email. There are no known risks associated with further participation in this study. All identifying information including your name and email address will be kept confidential by me, and will not be used in any publication or public presentation of this research.

Would you like to be contacted for further participation in this study? If so, please enter your name and email address in the field below. 


\section{VITA}

Alec D. Scherer, who will be joining the music education faculty at Texas State University in Fall 2020, earned a Bachelor of Music degree in Music Education and Performance (trumpet) from Lawrence University and a Master of Music degree in Performance from Boise State University. He will receive his $\mathrm{PhD}$ in Music Education from the University of Missouri in the spring of 2020. At the University of Missouri, he taught courses in the music education curriculum, supervised music student teachers, codirected the University Concert Band, and assisted with Marching Mizzou, the university's 300-member marching band. He began his teaching career in central Wisconsin, where he taught a comprehensive 6-12 band program.

Mr. Scherer has presented music education research at state and national venues. Recent presentations have included the Society for Music Teacher Education conference in Greensboro, North Carolina (2019) and the Missouri Music Educators Association Conference (2020). His research is published in the Journal of Music Teacher Education and the Missouri Journal of Research in Music Education. His research interests include democratic education in music, instrumental rehearsal techniques, instrumental conducting, and preservice teacher preparation. 